\title{
Modulation of Ionic Currents in Aplysia Motor Neuron B15 by Serotonin, Neuropeptides, and Second Messengers
}

\author{
Ronald Taussig, Alejandro Sweet-Cordero, and Richard H. Scheller \\ Department of Biological Sciences, Stanford University, Stanford, California 94305
}

\begin{abstract}
Both 5-HT and the 9 amino acid neuropeptide SCP $_{\mathrm{b}}$ modulate 3 ionic currents in B15, enhancing a voltage-dependent inward sodium current, decreasing an outward potassium current and increasing an inward rectifying potassium current. In contrast, FMRFamide decreases a voltage-dependent inward sodium current and increases an outward potassium current. We have also investigated the roles of several second-messenger systems that may be mediating the effects of these modulators. Bath application of membrane permeable analogs of cAMP enhance the voltage-dependent inward sodium current and both 5-HT and $\mathrm{SCP}_{\mathrm{b}}$ increase CAMP levels in B15, suggesting that CAMP may be mediating part of the observed effects of these transmitters on B15. Experiments with phorbol ester, a protein kinase inhibitor, and a phospholipase inhibitor suggest that the phospholipase $\mathrm{C}$ /protein kinase $\mathrm{C}$ cascade may decrease an outward potassium current. Thus, $5-\mathrm{HT}$ and $\mathrm{SCP}_{\mathrm{b}}$ may activate multiple second-messenger systems to modulate 3 ionic currents in B15. Additional studies suggest that a cascade involving arachidonic acid may be involved in mediating part of the FMRFamide responses in B15. These studies are beginning to define molecular mechanisms whereby a neuron differentially modulates multiple ionic currents in response to distinct chemical messengers.
\end{abstract}

Changes in the excitability of neuronal cells have been observed in response to synaptic or hormonal stimulation in many systems. These changes are often due to the modulation of specific ionic currents which are brought about by 2 general mechanisms. The first involves a process whereby an ion channel is directly gated by the binding of the ligand and is typified by the action of $\mathrm{ACh}$ on nicotinic receptors at the neuromuscular junction (reviewed by McCarthy et al., 1986). The second mechanism involves multicomponent systems where the receptor molecules are distinct from the ion channel. This process is generally thought to be mediated through second messengers by the action of guanine nucleotide binding (G) proteins (Gilman, 1987). Several second-messenger systems have been characterized to date, the best studied being those involving the cyclic nucleotides, cyclic AMP (reviewed by Ross and Gilman, 1980), and cyclic

Received Dec. 9, 1988; revised Feb. 9, 1989; accepted Mar. 10, 1989.

We would like to thank R. Aldrich, S. Thompson, and W. Sossin for critically reading the manuscript. This work is supported by a grant to R.H.S. from the NIMH. R.H.S. is a PEW Scholar and the recipient of a Presidential Young Investigator Award.

Correspondence should be addressed to Dr. Richard H. Scheller at the above address.

Copyright (C) 1989 Society for Neuroscience $0270-6474 / 89 / 093218-12 \$ 02.00 / 0$
GMP (Stryer, 1986). Other signaling pathways are mediated by products of phospholipid metabolism and include the diacylglycerol, inositol phosphate, and arachidonic acid systems (for reviews, see Irvine, 1982; Berridge, 1984).

Gaining insight into the mechanisms by which neurotransmitters act is central to an understanding of the cellular and molecular events that govern animal behaviors. In invertebrate species, biogenic amines and neuropeptides have been shown to modulate the output of defined neuronal circuits by altering specific ionic currents. For example, the amidated tetrapeptide Phe-Met-Arg-Phe-amide (FMRFamide), originally isolated from the venus clam (Price and Greenberg, 1979), has been shown to have a number of effects on ionic currents in central neurons, including changes in sodium, potassium, calcium, and chloride conductances (Cottrell, 1982; Cottrell et al., 1984; Boyd and Walker, 1985; Colombaioni et al., 1985; Rubin et al., 1986; Belardetti et al., 1987; Thompson and Ruben, 1988). The bioactive amine serotonin (5-HT) modulates a variety of potassium, chloride, sodium, and calcium currents in many central neurons of Aplysia and related mollusks (Gershenfeld and PaupardinTrisch, 1974; Klein and Kandel, 1980; Deterre et al., 1982; Benson and Levitan, 1983; Pellmar, 1984; Jacklet and AcostaUrquidi, 1985; Walsh and Byrne, 1985; Paupardin-Trisch et al., 1986; Kirk et al., 1988). 5-HT also plays a role in controlling several behaviors in Aplysia, including aspects of food-induced arousal (Weiss et al., 1978; Rosen et al., 1983) as well as sensitization and associative conditioning of the gill-, siphon-, and tail-withdrawal reflexes (Klein and Kandel, 1980; Kandel et al., 1983; Byrne, 1985; Carew and Sahley, 1986).

The small cardioactive peptide $\mathrm{b}\left(\mathrm{SCP}_{\mathrm{b}}\right)$ has been shown to have a number of activities in Aplysia, including stimulating contractile activity in the gut, increasing the amplitude of the heartbeat, and enhancing the contractile response of the ARC, muscle (for review, see Lloyd, 1986). In addition, $\mathrm{SCP}_{\mathrm{b}}$ has been shown to modulate several potassium and calcium currents in central neurons of Aplysia and other mollusks (Abrams et al., 1984; Acosta-Urquidi, 1988).

Feeding behavior in Aplysia is useful for investigating cellular mechanisms that underlie animal behaviors. This behavior is comprised of a number of different motor patterns, including orientation, biting, swallowing, and rejection (Kupfermann, 1974; Weiss et al., 1986). Among the motions involved in feeding is a rhythmic protraction and retraction of the radula which is used to grasp food. One of the muscles involved in retracting the radula is the accessory radular closure (ARC) muscle which is innervated by 2 identifiable motor neurons, B15 and B16 located in the buccal ganglion (Cohen et al., 1978; Weiss et al., 1978). B15 and B16 receive input from a number of cells, in- 
cluding cholinergic buccal interneurons B4 and B5 and the serotonergic metacerebral cell (MCC) situated in the cerebral ganglion (Gardner, 1971, 1977; Schwartz and Shkolnik, 1981; Rosen et al., 1982; Jahan-Parwar et al., 1983). The MCC produces heterosynaptic enhancement of EJPs at the neuromuscular junction of B15 (Weiss et al., 1978). Immunological, biochemical, and molecular genetic techniques have been used to localize several neuromodulators, including FMRFamide (Schaefer et al., 1985; Lloyd et al., 1987), SCP $_{\mathrm{b}}$ (Lloyd et al., 1985; Mahon ct al., 1985), and 5-HT (Goldstcin et al., 1984) to the buccal ganglion and $\mathrm{ARC}$ muscle. In contrast to the activity of the MCC cell, FMRFamide produces heterosynaptic depression of the EJPs produced by B15 and B16. Sossin et al. (1987) have shown in vitro that $\mathrm{B} 15$ is directly excited by $5-\mathrm{HT}$ as well as $\mathrm{SCP}_{\mathrm{b}}$ and that this neuron is directly inhibited by FMRFamide. These studies suggest that in vivo B15 may indeed receive modulatory input from neurons that release these transmitters.

The modulation of ionic currents in B15 is likely to have profound effects on the synaptic release of classical and peptide transmitters synthesized in this neuron. We are interested in defining cellular mechanisms used to generate the responses of B15 to this variety of modulatory substances. Voltage-clamp and biochemical techniques were employed to investigate the roles of modulatory transmitters, as well as a number of secondmessenger systems that may be mediating the responses. We show here that 5-HT, $\mathrm{SCP}_{\mathrm{b}}$, and FMRFamide induce changes in a number of different ionic currents in $\mathrm{B} 15$ that are mediated by several distinct second-messenger systems.

\section{Materials and Methods}

All experiments were performed on Aplysia californica (75-200 gm) purchased from Sea Life Supply (Seaside, CA). Generally, before dissection the animals were anesthetized by injection with isotonic $\mathrm{MgCl}_{2}$ equivalent to $50 \%$ of their body weight. The physiological experiments were performed at room temperature $\left(22-25^{\circ} \mathrm{C}\right)$. The mean data $( \pm \mathrm{SD})$ are presented. Prior to intraccllular recording, the sheaths overlying the rostral surfaces of the buccal ganglia were removed. Cells were used only if they had a resting membrane potential of at least $-40 \mathrm{mV}$. B15 was voltage-clamped with 2 microelectrodes using a voltage clamp similar to that described by Barish and Thompson (1983).

The cell's membrane potential was recorded differentially between the voltage-sensing microelectrode filled with $3 \mathrm{M} \mathrm{KCl} \mathrm{(3-8} \mathrm{M \Omega )} \mathrm{and} \mathrm{a}$ saline-agar bridge placed in the bath. The current-passing electrode was filled with 3 м potassium acetate $(5-10 \mathrm{M} \Omega$ ), and current was monitored with a virtual ground circuit. The signals from the virtual ground were low-pass filtered with an 8-pole Bessel filter (Freq. Dev., Inc.). Cutoff frequencies were $10-100 \mathrm{~Hz}$ for measurements of currents during $1 \mathrm{sec}$ (or longer) voltage pulses and $1 \mathrm{kHz}$ for all other current measurements. Current recordings were digitized at $1 \mathrm{kHz}$ and stored on diskettes.

For the construction of $I-V$ curves, the cells were clamped at a holding potential of $-50 \mathrm{mV}$ and once every $4 \mathrm{sec}$, the voltage was stepped to potentials between -100 and $-5 \mathrm{mV}$ in $5 \mathrm{mV}$ increments for a duration of $1 \mathrm{sec}$. The currents measured at the end of each $1 \mathrm{sec}$ pulse (with reference to absolute zero current determined at the start of each experiment) were plotted as a function of the step voltage. The effects of 5-HT, $\mathrm{SCP}_{\mathrm{b}}$, and FMRFamide on the transient potassium current $I_{\mathrm{A}}$ were examined by measuring the peak currents elicited by $500 \mathrm{msec}$ test pulses to $-40,-35,-30,-25,-20$, and $-15 \mathrm{mV}$ preceded by a $3 \mathrm{sec}$ prepulse to $-70 \mathrm{mV}$ to remove inactivation of this current. Effects of these agents on the delayed potassium current $\left(I_{\mathrm{K}}\right)$ were determined by measuring the peak currents in response $250 \mathrm{msec}$ test pulses to 0 and $10 \mathrm{mV}$ following a 6-10 sec prepulse at a holding potential of -40 $\mathrm{mV}$. Delivery of voltage pulses, data acquisition, and analysis were performed with an IBM PC AT using software purchased from Axon Instruments (pCLAMP). Stored current traces were also reproduced with an HP plotter (7470A).

Solutions. The normal artificial seawater (ASW) solution had the following composition: $490 \mathrm{mM} \mathrm{NaCl} / 11 \mathrm{~mm} \mathrm{KCl} / 19 \mathrm{mM} \mathrm{MgCl} / 30$ $\mathrm{mm} \mathrm{MgSO}_{4} / 11 \mathrm{~mm} \mathrm{CaCl} / 10 \mathrm{~mm}$ Tris $\mathrm{HCl}, \mathrm{pH}$ 7.6. In sodium-free salines, sodium was replaced with equimolar amounts of $N$-methyl-DGlucamine (NMDG, from Sigma, $\mathrm{pH}$ adjusted to 7.6 with concentrated hydrochloric acid). When used, $\mathrm{CsCl}(10-20 \mathrm{~mm})$ was added hypertonically to the saline. To block chemical synaptic transmission, the salines contained $30 \mathrm{~mm} \mathrm{CoCl}$ added hypertonically or replacing $\mathrm{CaCl}_{2}$. The solutions containing $\mathrm{CoCl}_{2}$ effectively blocked inward calcium currents (and the calcium-activated potassium current, data not shown), and blocked all chemically mediated synaptic transmission, ensuring that the results observed were due to direct effects.

Concentrated stock solutions of the following substances were made in distilled water and diluted into the bath at the concentrations indicated: FMRFamide (Peninsula Labs), 10-50 $\mu \mathrm{M}$; $\mathrm{SCP}_{\mathrm{b}}$ (Peninsula Labs), 10-50 $\mu \mathrm{M} ; 8$-bromo-adenosine-3':5' cyclic monophosphate (Sigma, 8-bromo-cyclic AMP), 250-500 $\mu$ M. 5-IIydroxytryptamine creatine sulfate complex (5-HT, Sigma) was prepared fresh daily in the appropriate saline and added to the bath to final concentrations between 10 and $100 \mu \mathrm{M}$. The concentrations of these agents were consistent with those used in previous studies on motor neurons B15 and B16 (Kirk and Scheller, 1986; Sossin et al., 1987; Kirk et al., 1988). H-7 [1-(5-isoquinolinesulfonyl)-2-methylpiperazine dihydrochloride, Seikagaku America, Inc.] was dissolved in distilled water and diluted to $25 \mu \mathrm{M}$ in the appropriate test saline.

Phorbol, phorbol dibutyrate (PDBU), and phorbol myristate acetate (PMA, all purchased from Sigma) were dissolved in dimethyl sulfoxide (DMSO) and diluted directly into the appropriate test salines to final concentrations between 10-100 nм (from DeRiemer et al., 1983). The final concentration of DMSO was $<0.01 \%$. Stock solutions of 4-bromophenacyl bromide (4BPAB) were prepared fresh daily in DMSO and dissolved into ASW at concentrations between 40 and $100 \mu_{\mathrm{M}}$ (DMSO concentration $<0.04 \%$ ). In control experiments, application of DMSO at these concentrations had no obvious adverse effects on membrane currents, nor did pretreatment of preparations with DMSO interfere with the responses to $5-\mathrm{HT}, \mathrm{SCP}_{\mathrm{b}}$, or FMRFamide.

Several substances were injected intracellularly with pressure pulses (10-50 msec, 10-25 psi) using a Picospritzer II (General Valve Corp.). Electrodes for pressure injection were filled with Fast Green $(0.1 \%)$ and one of the substances below. Fast green was used to allow visual verification that solutions were being injected into the neurons. A single pressure pulse delivered $0.02-0.3 \mathrm{nl}$ of solution as determined using a modification of the method of McCamen et al. (1977). Control injections of Fast green dissolved in distilled water or normal ASW had no obvious cffcets on the membrane current. Arachidonic acid (Sigma) was prepared according to the protocol of Piomelli et al. (1987) and injected at a concentration of $50 \mu \mathrm{M}$. Inositol trisphosphate ( $\mathrm{IP}_{3}$, from Sigma) was dissolved in distilled water and injected at concentrations between 0.5 and $5 \mathrm{~mm}$ (from Sawada et al., 1987). For the generation of $I-V$ curves during the response of $\mathrm{B} 15$ to either $\mathrm{IP}_{3}$ or arachidonic acid, the solutions were delivered by injecting a single pressure pulse $1 \mathrm{sec}$ before each voltage step command.

Aplysia egg-laying hormone (ELH) was purified from crude preparations of synthetic peptide (Peninsula Labs) using HPLC. The peak containing ELH was lyophilized, dissolved in distilled water, and stored at $-70^{\circ} \mathrm{C}$ until used. Aliquots $(5-25 \mu \mathrm{l})$ of these ELH stock solutions were brought to room temperature and applied at final concentrations between 0.2 and $1 \mu \mathrm{M}$.

cAMP determination. Following the identification of buccal motor neurons $\mathrm{B} 15$ and $\mathrm{B} 16$, the desheathed buccal ganglia were perfused with either calcium-free ASW or calcium-free ASW containing $\mathrm{CoCl}_{2}$ for 15 min. $\operatorname{SCP}_{\mathrm{b}}(10 \mu \mathrm{M}), \operatorname{ELH}(0.2-1 \mu \mathrm{M})$, or 5-HT $(10 \mu \mathrm{M})$ was applied to the bath and after a designated time $(8,8$, or $5 \mathrm{~min}$, respectively), the ganglion was fixed in $50 \%$ propylene glycol $/ 2 \mathrm{M} \mathrm{NaCl}$ at $-20^{\circ} \mathrm{C}$ for 30 min as described by Bernier et al. (1982). Individual B15 and B16 neurons were dissected out and stored at $-70^{\circ} \mathrm{C}$.

Four B 15 or B16 cells that were similarly treated were pooled for each sample. Samples were thawed at $0^{\circ} \mathrm{C}$, sonicated in $40 \mu \mathrm{l} 6 \% \mathrm{TCA}$, and centrifuged at $5000 \mathrm{rpm}$ for $10 \mathrm{~min}$. Ten percent of the supernatant as well as the remaining pellet was subjected to protein determination using a modification of the fluorescamine method (Newcomb, 1983) originally described by Udenfriend et al. (1972). The amount of protein in each sample was determined by comparison to a standard curve derived from similarly treated aliquots of glycine of known concentrations. The remaining $90 \%$ of the supernatant was adjusted to $100 \mu \mathrm{l}$ with $6 \%$.TCA and subjected to cAMP determination using a radioimmune assay as per manufacturers specifications (Amersham). Cyclic 
A
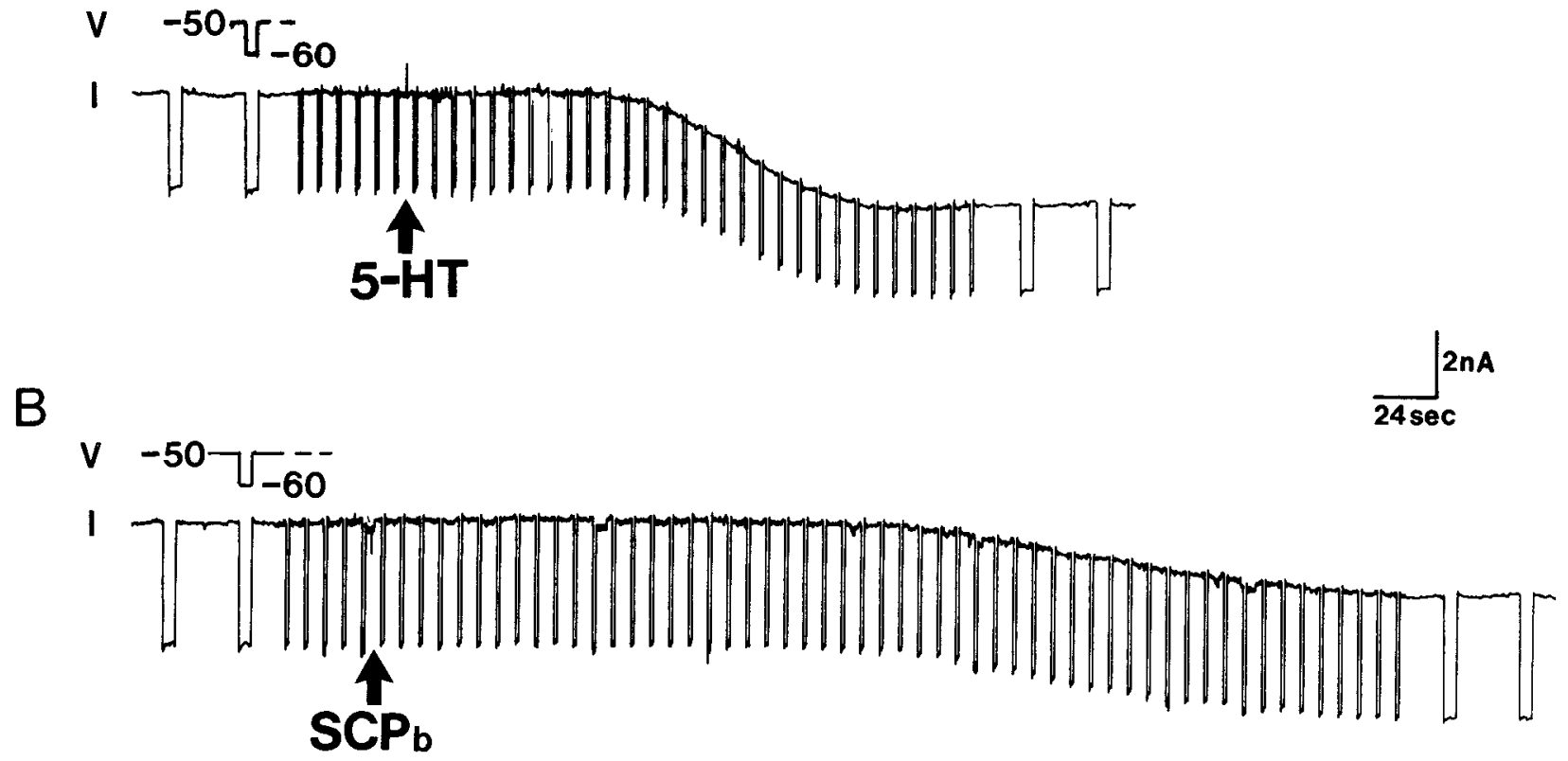

C

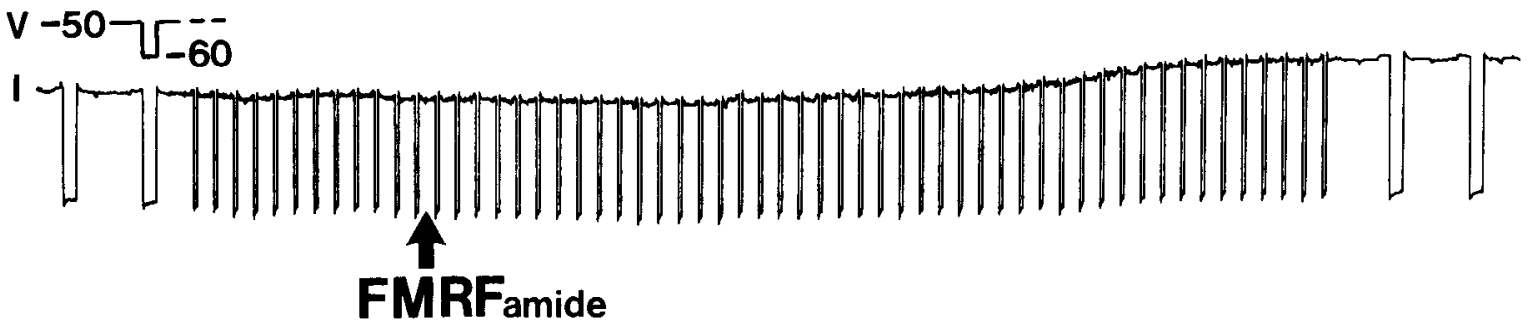

Figure 1. Responses to 5-HT, $\mathrm{SCP}_{\mathrm{b}}$, and FMRFamide in motor neuron B15 recorded during voltage clamp. In all 3 preparations shown, the cells were held at a potential of $-50 \mathrm{mV}$ and a $1 \mathrm{sec} 10 \mathrm{mV}$ hyperpolarizing step was applied every $4 \mathrm{sec}$ as illustrated in the top traces of each of the 3 panels $(V)$. Current responses were recorded with a virtual ground amplifier and are shown below the sample voltage steps $(I)$. $A$, 5 -HT was applied to the bathing saline at the arrow; note the inward shift in the holding current with a short latency after addition of the transmitter. $B$, $\mathrm{SCP}_{\mathrm{b}}$ was bath applied to a different preparation at the arrow. $\mathrm{SCP}_{\mathrm{b}}$ induces an inward shift in the holding current similar to that caused by 5 - $\mathrm{HT}$; however, the response takes longer to develop. $C$, In a third preparation, FMRFamide was bath applied at the arrow and caused an outward shift in the holding current. In all 3 current traces, the first and last steps were recorded at 5 times faster chart speed.

AMP levels are reported as the median followed by the range of the values (fmol cAMP/nmol protein/cell). Statistically significant increases of cAMP levels in experimentally treated cells compared to control levels were determined using the Mann-Whitney $U$ test.

\section{Results}

B15 was voltage-clamped at a potential of $-50 \mathrm{mV}$ and repeated steps to $-60 \mathrm{mV}$ were applied. Under these conditions, bath application of $10 \mu \mathrm{M} 5$-HT (at arrow, Fig. 1A) or $10 \mu \mathrm{M} \mathrm{SCP}$ (at arrow, Fig. $1 B$ ) caused an inward shift in the holding current. The time to response for the 5-HT treatment was consistently shorter $(3.4 \pm 0.22 \mathrm{~min}, n=6)$ than for the $\mathrm{SCP}_{\mathrm{b}}$ treatment $(6.0 \pm 3.1 \mathrm{~min}, n=12)$; however, the magnitude of the changes in the holding current were very similar $(-3.1 \pm 0.7$ and -2.8 $\pm 1.6 \mathrm{nA}$, respectively). In addition, neither 5-HT nor $\mathrm{SCP}_{\mathrm{b}}$ caused substantial changes in the amplitude of the step current. In contrast, bath application of $10 \mu \mathrm{M}$ FMRFamide resulted in an outward shift in the holding current with a time of response of $5.8 \pm 1.0 \mathrm{~min}(n=8$; Fig. $1 C$ ). In addition, FMRFamide consistently caused a marked increase in the amplitude of the step current.
The different time courses of the observed responses may be due to different modes of action of these 3 transmitters, different relative threshold concentrations of transmitters which are required for the responses, or differences in the diffusion rates of these substances through the bath or connective tissue of the ganglion. To characterize the modulation of specific ionic currents by these 3 transmitters, current-voltage relationships were derived for $\mathrm{B} 15$ in response to these agents in a variety of external bathing salines.

\section{5-HT and $\mathrm{SCP}_{b}$ enhance a voltage-dependent inward sodium current $I_{I N}$}

Current-voltage relationships were constructed before, during, and after washout of the responses to 5-HT (Fig. 2A) or $\mathrm{SCP}_{\mathrm{b}}$ (Fig. $2 C$ ). In these examples, B15 was voltage-clamped and the voltage was stepped to potentials between -80 and $-5 \mathrm{mV}$ for $1 \mathrm{sec}$ (from a holding potential of $-50 \mathrm{mV}$ ), and the current responses at these step voltages were recorded. Representative current traces are illustratcd in the insets of Figures $2, A, C$. The current measured at the end of each $1 \mathrm{sec}$ pulse (with reference 
A

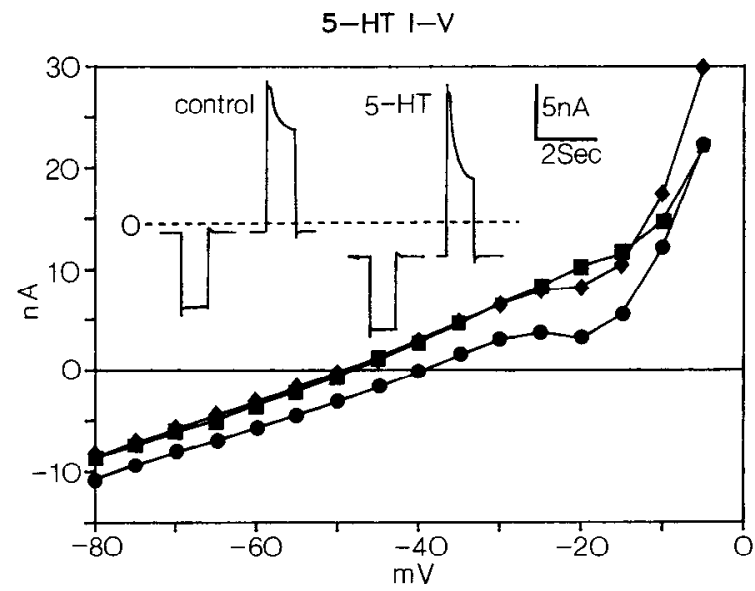

B

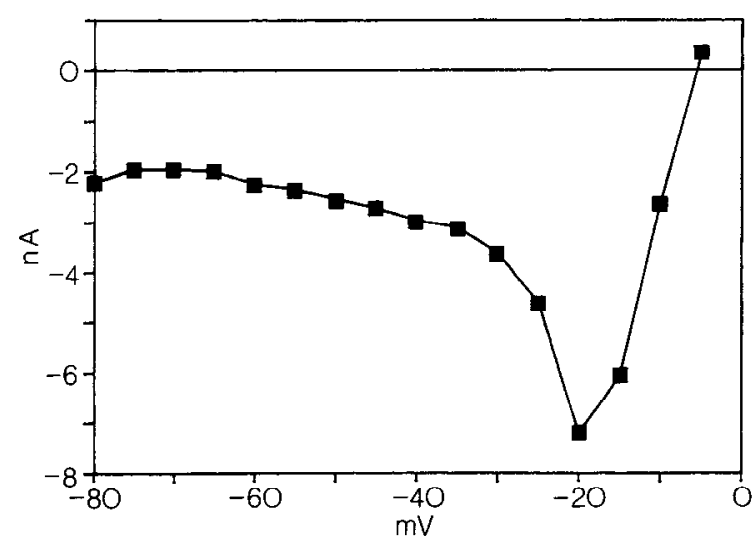

C

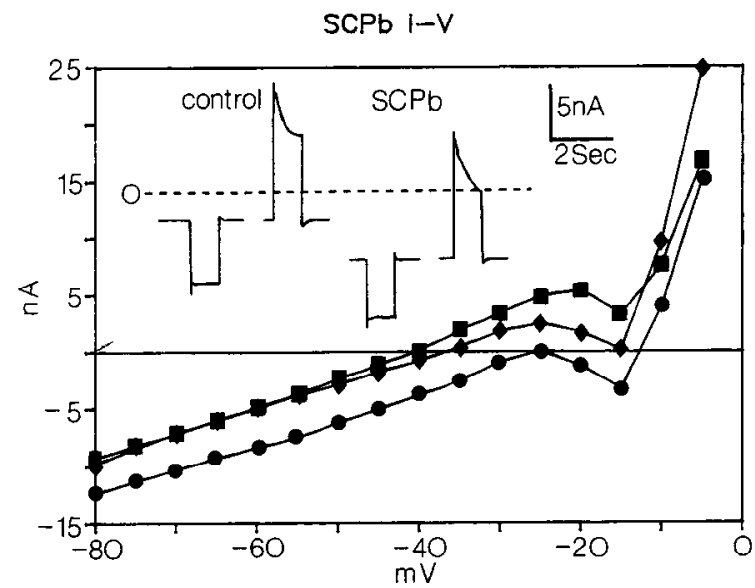

D

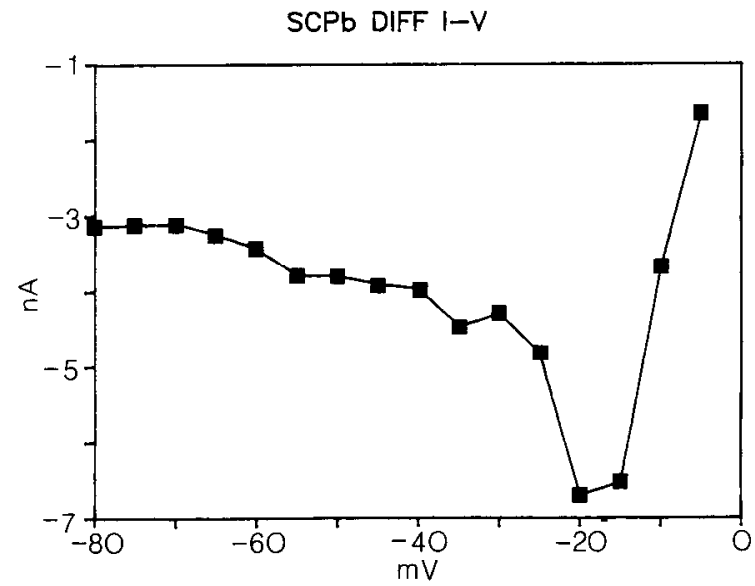

Figure 2. Effects of the excitatory transmitters, 5-HT and $\mathrm{SCP}_{\mathrm{b}}$ on ionic currents in $\mathrm{B} 15$. $A$, The quasi-steady-state current values measured at the tail end of a $1 \mathrm{sec}$ test voltage pulse is plotted as a function of the step voltage $(\boldsymbol{\square}$, control; $\boldsymbol{\theta}, 5 \mathrm{~min}$ after the addition of 5 -HT to the preparation; $\checkmark, 20 \mathrm{~min}$ following continuous perfusion with normal ASW). Inset, Sample current tracings in response to voltage steps to -75 and $-25 \mathrm{mV}$ during the control and experimental conditions (i.e., after addition of $5-\mathrm{HT}$ ). $B$, The difference $I-V$ curve for the experiment shown in $A$. Note the enhancement of a voltage-dependent inward current maximally active in the voltage range of -30 to $-15 \mathrm{mV}$. $C, \operatorname{Same}$ as $A$, only SCP $\mathrm{b}_{\mathrm{b}}$ was applied. $D$, The difference $I-V$ curve for the experiment shown in $C$. Note the similarity of this curve to that in $B$.

to zero current) was plotted as a function of the step voltage for each of the experimental conditions (i.e., before, during, and after addition of 5-HT or $\mathrm{SCP}_{\mathrm{b}}$ ). The difference $I-V$ curves for these experiments were constructed by subtracting the $I-V$ curves in the control condition from the $I-V$ curves obtained during the response and are presented in Figure $2 B$ and $2 D$, respectively. Other recordings suggest the presence of additional currents as seen by Kirk et al. (1988) and discussed below.

One prominent feature of these different $I-V$ curves is the enhancement by both $5-\mathrm{HT}$ and $\mathrm{SCP}_{\mathrm{b}}$ of a voltage-dependent inward current that is maximally active in the voltage range from -30 to $-15 \mathrm{mV}$. The peak amplitude of this component is $-6.9 \pm 0.7$ and $-5.8 \pm 2.2 \mathrm{nA}$ for $5-\mathrm{HT}$ and $\mathrm{SCP}_{\mathrm{b}}$, respectively. A second prominent feature of these difference $I-V$ curves is the enhancement of a more voltage-independent inward component active at more hyperpolarizing potentials. The magnitude of this component (measured at $-60 \mathrm{mV}$ ) is $-2.9 \pm 0.7$ $\mathrm{nA}$ for the 5-HT responses and $-2.8 \pm 1.7 \mathrm{nA}$ for $\mathrm{SCP}_{\mathrm{b}}$. The enhancement of both of these components was observed in 8 out of 8 preparations to which 5 -HT was applied, and 18 out of 18 preparations treated with $\mathrm{SCP}_{\mathrm{b}}$.

The sodium dependence of these components was demon- strated by conducting the same experiments in sodium-free salines. When sodium was replaced with equimolar NMDG in the external saline, no enhancement of either of these components was ever observed in 345 -HT treated cells (see Fig. $3 \mathrm{~A}$ ) or 23 preparations treated with $\mathrm{SCP}_{\mathrm{b}}$ (see Fig. $3 C$ ). We conclude that in $\mathrm{B} 15, \mathrm{SCP}_{\mathrm{b}}$ and $5-\mathrm{HT}$ increase $I_{\mathrm{IN}}$, an inward sodium current that is maximally active in the -30 to $-15 \mathrm{mV}$ range. This current has an additional component that is active at more negative potentials and resembles the cyclic nucleotide-activated sodium current described by Green and Gillette (1983) and Connor and Hockberger (1984).

\section{Both 5-HT and $S C P_{b}$ additionally modulate 2 potassium} currents

Inspection of Figure 3, $A, C$ reveals additional effects of both 5-HT and $\mathrm{SCP}_{\mathrm{b}}$ on $\mathrm{B} 15$. In fact, both of these difference $I-V$ curves can be accounted for by the combined effects on 2 potassium currents. At potentials below $-70 \mathrm{mV}$, the effect of both $5-\mathrm{HT}$ and $\mathrm{SCP}_{\mathrm{b}}$ was to increase an inwardly rectifying potassium current (discussed below and in Fig. $6 B$ ) which is completely blocked by the addition of $10 \mathrm{~mm}$ cesium to the external bathing saline (Fig. 3, $A, C$ ). 
A

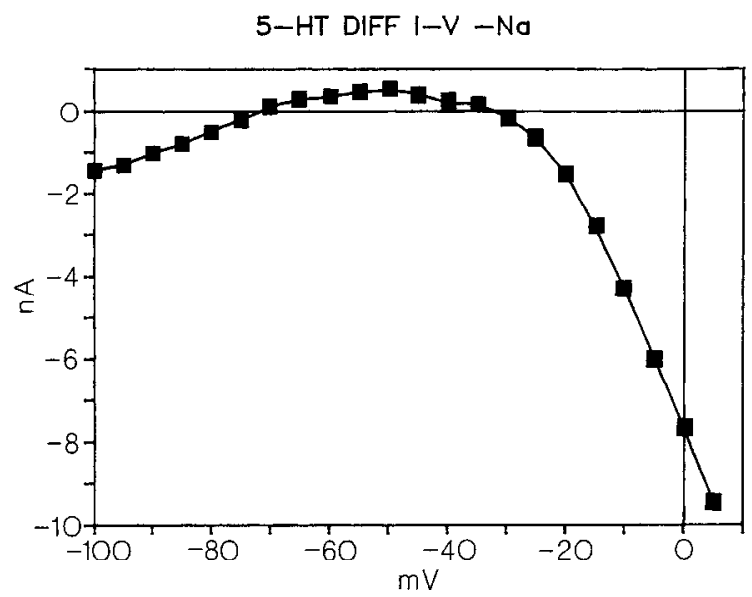

B

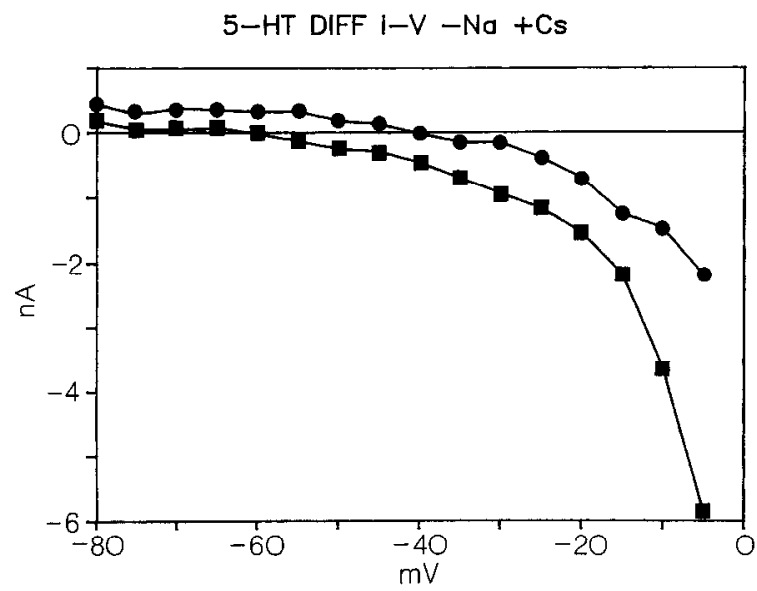

C

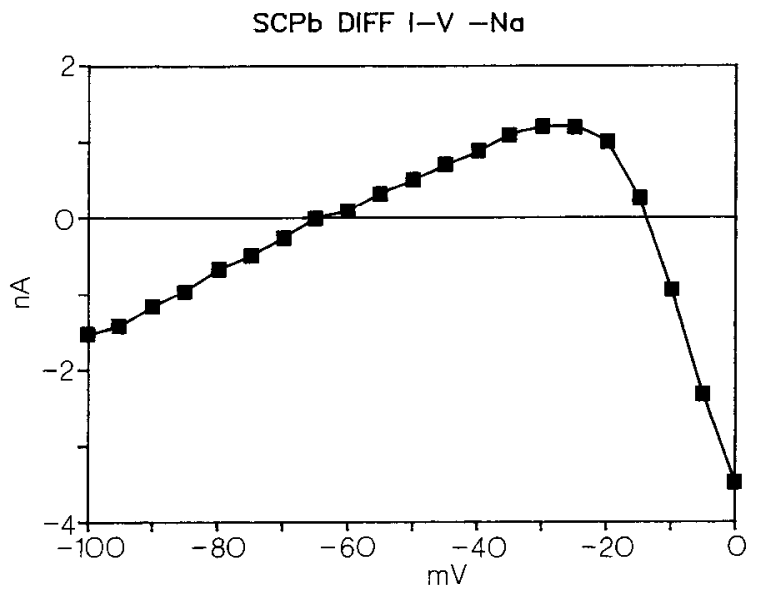

D

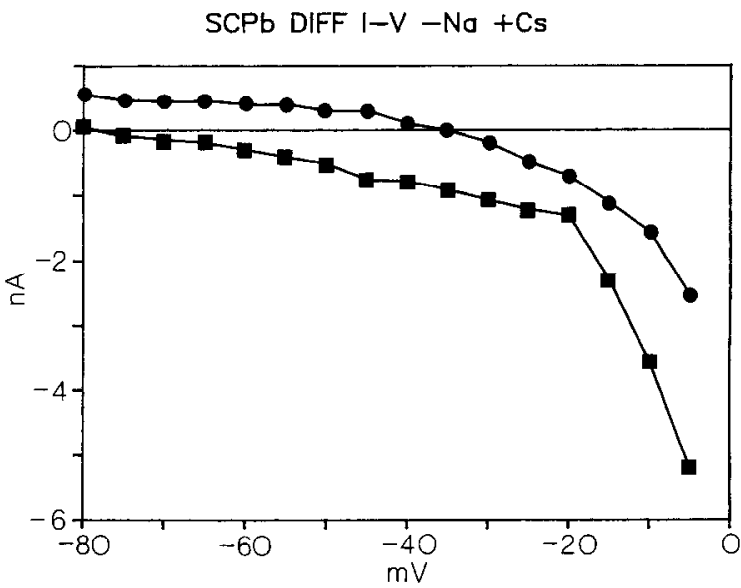

Figure 3. Difference $I-V$ relations illustrating the effects of the excitatory transmitters on $\mathrm{B} 15$ in sodium-free salines. $A$, Difference $I-V$ curve for an experiment in which 5-HT was applied to a preparation bathed in sodium-free saline. Note that the voltage-dependent inward component shown in Figure $2 B$ is eliminated in salines in which external sodium has been replaced with NMDG. The resulting difference $I-V$ curve is composed of an inwardly rectifying current (at voltages below $-65 \mathrm{mV}$ ) and a second inward current active at more depolarizing voltages. $B$, Difference $I-$ $V$ curves for experiments carried out in sodium-free salines containing cesium. The effect of 5-HT on the inward rectifying current is eliminated by cesium. The remaining current is shown for 2 preparations where the external potassium has been varied from $11 \mathrm{~mm}(\mathbb{C})$ to $55 \mathrm{~mm}(\bullet)$. $C$, Same as $A$ except $\mathrm{SCP}_{\mathrm{b}}$ was added to a different preparation. $D$, Same as $B$ except $\mathrm{SCP}_{\mathrm{b}}$ was bath applied to the preparations.

In sodium-free salines containing cesium, a third current modulated by 5 -HT and $\mathrm{SCP}_{\mathrm{b}}$ can be observed in isolation as illustrated in Figure 3, $B$ and $D$, respectively. The effect of both 5-HT and $\mathrm{SCP}_{\mathrm{b}}$ in these salines was to generate a net inward current by decreasing an outward potassium current. The potassium dependence of this current was demonstrated by measuring the reversal potential of the $5-\mathrm{HT}$ and $\mathrm{SCP}_{b}$ effects at different external potassium concentrations. For a 5 -fold increase in potassium concentration, the predicted change in the reversal potential is $+40 \mathrm{mV}$. The reversal potential for the 5-HT effect (taken as the point of the curve that crosses the difference current axis) is $-64 \pm 8 \mathrm{mV}(n=7)$ in saline containing normal potassium $(11 \mathrm{~mm})$ and shifts to $-35 \pm 2.5 \mathrm{mV}$ $(n=6)$ in 5 times normal potassium $(55 \mathrm{~mm})$ (Fig. $3 B)$. Similarly, the reversal potential for the $\mathrm{SCP}_{\mathrm{b}}$ induced change in this current is $-60 \pm 11.8 \mathrm{mV}(n=5)$ in normal and $-36 \pm 4.3 \mathrm{mV}(n=$ 4 ) in 5 times normal potassium (Fig. $3 D$ ). In addition, reversal potentials for 2 preparations treated with $5-\mathrm{HT}$ and 2 treated with $\mathrm{SCP}_{\mathrm{b}}$ were not measured (the difference $I-V$ curve failed to cross the zero difference current axis) and may reflect the poor ability of the channels to pass inward current. We have called this the S-like current by analogy to the 5-HT and SCP $_{b}$ sensitive current characterized in Aplysia sensory neurons (Klein et al., 1982; Abrams et al., 1984).

The effects of 5-HT and $\mathrm{SCP}_{\mathrm{b}}$ on other potassium currents in B15 were examined; neither of these transmitters had any consistent effect on the delayed outward potassium current, $I_{\mathrm{K}}$, or the transient potassium current, $I_{\mathrm{A}}$. We conclude that the principal effects of 5-HT and $\mathrm{SCP}_{\mathrm{b}}$ on B15 are 3-fold: an enhancement of a voltage-dependent inward sodium current $\left(I_{\mathrm{IN}}\right)$, an inward rectifying potassium current $\left(I_{\text {INREC }}\right)$, and a decrease in an outward potassium current $\left(I_{\mathrm{S}}\right)$.

\section{Effects of FMRFamide on ionic currents in B15}

The $I-V$ curves for a preparation in normal ASW before, during, and after washout of bath applied FMRFamide are illustrated in Figure $4 A$. Examination of the difference $I-V$ curve for this experiment reveals a complicated curve which reaches a peak in the -25 to $-15 \mathrm{mV}$ range $(n=5)$. This peak was completely abolished in sodium-free salines $(n=16$, compare B and the 
curve in Fig. 4C). This suggests that one of the effects of FMRFamide on B15 is to reduce the voltage-dependent inward sodium current $\left(I_{\mathrm{IN}}\right)$.

FMRFamide also increased an S-like outward potassium current in B15. Figure $4 C$ reveals the potassium dependence of the FMRFamide effect in sodium-free salines. The reversal potential for this FMRFamide effect shifted from $-64 \pm 5.6 \mathrm{mV}(n$ $=10)$ in $11 \mathrm{~mm}$ potassium to $-34 \pm 1.1 \mathrm{mV}(n=6)$ in $55 \mathrm{~mm}$ potassium. In addition, for 2 experiments performed in $11 \mathrm{~mm}$ potassium, we failed to measure a reversal potential.

FMRFamide, like 5-HT and $\mathrm{SCP}_{\mathrm{b}}$, had no effect on the transient potassium current $I_{\mathrm{A}}$ or the delayed outward potassium current $I_{\mathrm{K}}$. Unlike 5-HT and $\mathrm{SCP}_{\mathrm{b}}$, FMRFamide had no effect on the inward rectifying potassium current $(n=16)$. Therefore, in B15, FMRFamide modulates 2 of the same (or similar) currents as $\mathrm{SCP}_{\mathrm{b}}$ and 5-HT but in the opposite direction; FMRFamide decreases $I_{\mathrm{IN}}$ and increases an S-like potassium current.

Cyclic AMP mediates the $S C P_{b}$ and 5-HT enhancement of $\mathrm{I}_{I N}$

We have examined the roles of several putative second-messenger systems in mediating the observed responses in B15 to 5-HT, $\mathrm{SCP}_{\mathrm{b}}$, and FMRFamide. Bath application of the membrane-permeable analog of cAMP, 8-bromo-cAMP caused the enhancement of a voltage-dependent inward current in B15 ( $n$ $=4$ ) as shown in Figure $5 \mathrm{~A}$. The calculated reversal potential for this response from the 4 preparations is $+30 \pm 27.8 \mathrm{mV}$ (as determined by extrapolating the curves to the point where they cross the zero difference current axis).

This response has several features in common with those of 5-HT and $\mathrm{SCP}_{\mathrm{b}}$. First, this inward current is maximally active in the -30 to $-15 \mathrm{mV}$ range (peak current $=-6.5 \pm 0.6 \mathrm{nA}$ ). Second, at more negative voltages, a more voltage-independent inward component was consistently observed (with a magnitude of $-2.3 \pm 1.1$ at $-60 \mathrm{mV}$ ). In addition, in sodium-free saline, the response to 8-bromo-cAMP was abolished; however, unlike the $5-\mathrm{HT}$ or $\mathrm{SCP}_{\mathrm{b}}$ responses in $\mathrm{B} 15$, no other effect by this agent was observed with the absence of sodium from the bathing saline $(n=3)$. These experiments suggest that in $\mathrm{B} 15$, the effects of $5-\mathrm{HT}$ and $\mathrm{SCP}_{\mathrm{b}}$ on $I_{\mathrm{IN}}$ (but not the effects on the potassium currents) may be mediated by cAMP. Similar observations by Kirk et al. (1988) have led to the proposal that in buccal motor neuron B16, which also innervates the ARC muscle, cAMP or cGMP may mediate the ELH and 5-HT enhancement of $I_{\mathrm{IN}}$.

To explore these possibilities further, we have used a radioimmune assay to determine the effects of these transmitters on the levels of CAMP in motor neurons B15 and B16. Our results for B15 are summarized in Figure $5 B$. Significant incrcases $(p<$ 0.005 ) in cAMP levels in B15 were measured in response to hath application of 5-HT (median, 14; range, 7-19 fmol cAMP/ $\mathrm{nmol}$ protein/cell) or $\mathrm{SCP}_{\mathrm{b}}(62,31.2-137)$ over control levels $(2.3,0.5-5.1)$. In contrast, bath application of ELH caused a small, statistically nonsignificant increase $(2.5,2.2-4.4, p>0.1)$ in cAMP levels in B15.

Somewhat puzzling was the observation that while both 5-HT and $\mathrm{SCP}_{\mathrm{b}}$ cause a similar enhancement of $I_{\mathrm{IN}}, \mathrm{SCP}_{\mathrm{b}}$ produced a 5-fold greater increase in cAMP levels than 5-HT. One possible reason for this discrepancy may be that, in an attempt to control for the differences between the response times of $\mathrm{B} 15$ to these agents, cells were treated with $\mathrm{SCP}_{\mathrm{b}}$ for longer periods of time prior to cAMP determination (see Materials and Methods). Alternatively, $\mathrm{SCP}_{\mathrm{b}}$ may indeed be more potent than $5-\mathrm{HT}$ in raising cAMP levels in B15; however, $I_{\mathrm{IN}}$ may be maximally
A

FMRF $1-\mathrm{V}$

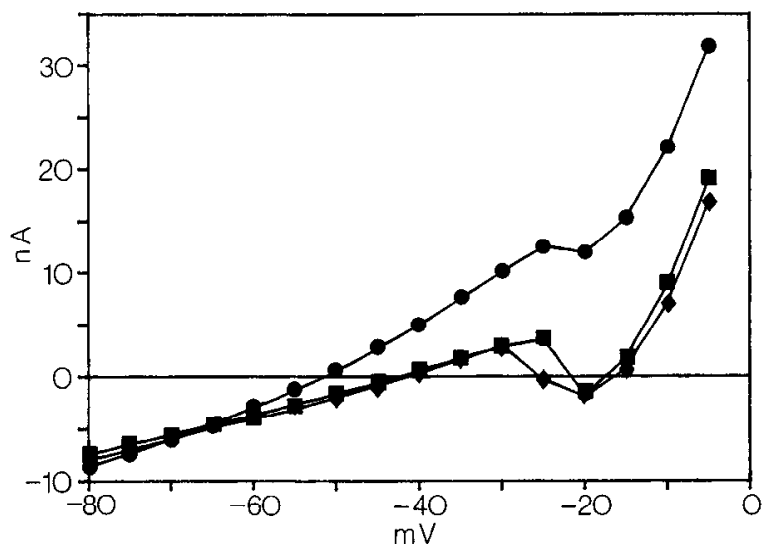

B

FMRF DIFF $1-\mathrm{V}$

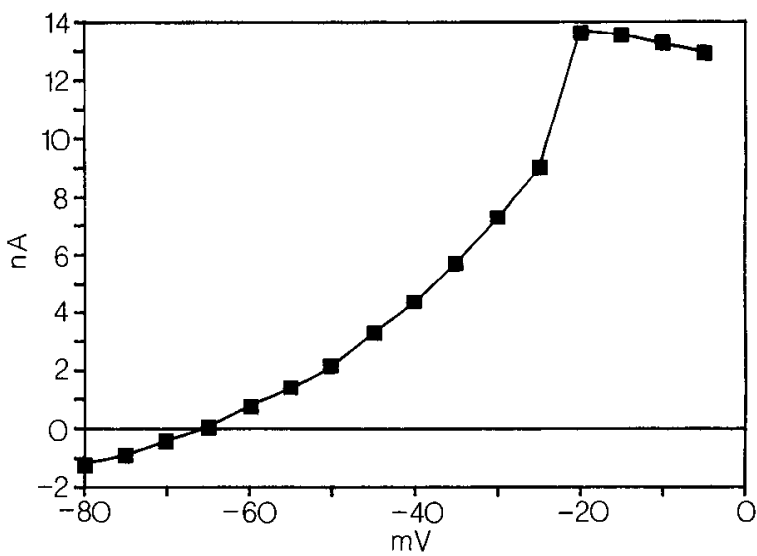

C

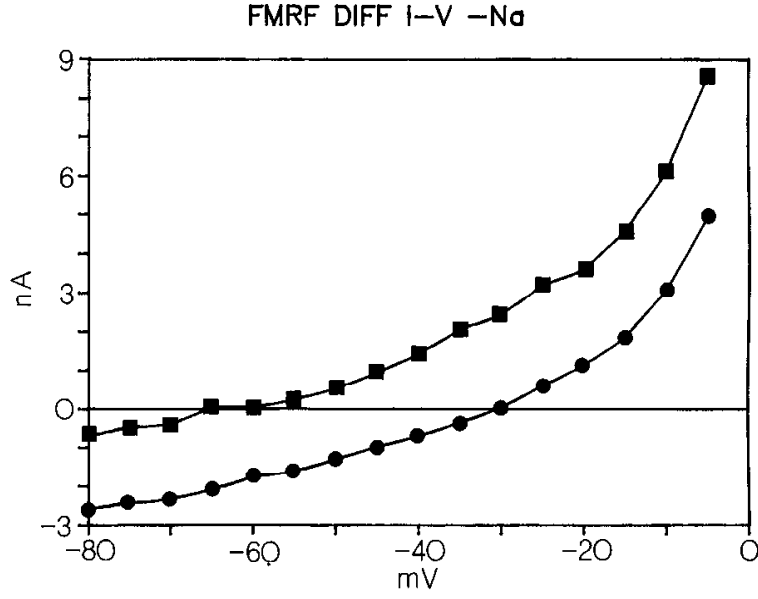

Figure 4. Effects of the inhibitory transmitter, FMRFamide on ionic currents in B15. $A$, Current-voltage curves from an experiment performed in normal ASW for control ( $\square$ ), $8 \mathrm{~min}$ after the addition of FMRFamide (@) and after $10 \mathrm{~min}$ of continuous perfusion with normal ASW $(\diamond) . B$, Difference $I-V$ curve for the above preparation. $C$, Difference $I-V$ curves for 2 experiments carried out in sodium-free salines. The records shown are for 2 applications of FMRFamide to the same cell in which the external potassium concentration was $11 \mathrm{~mm}(\square)$ or $55 \mathrm{~mm}(0)$. Note that the voltage-dependent outward current, which is maximally active in the -30 to $-10 \mathrm{mV}$ range $(B)$, is eliminated in sodium-free salines. 
A

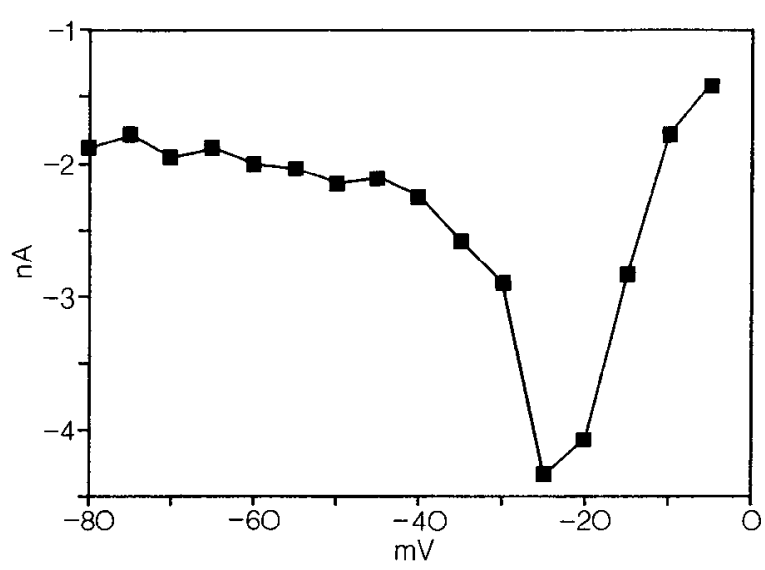

B

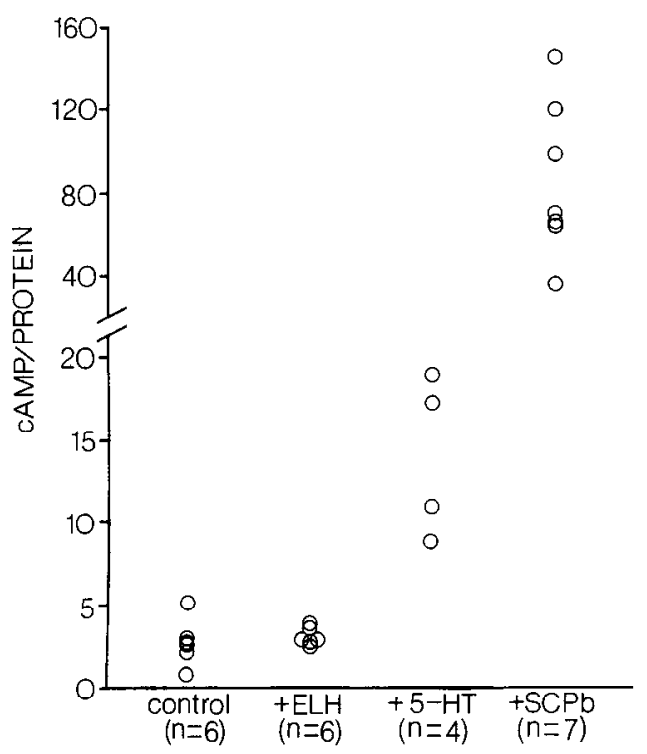

Figure 5. The role of cAMP in mediating the effects of 5-HT and $\mathrm{SCP}_{\mathrm{b}}$ in B15. $A$, Difference $I-V$ curve for a preparation to which 8-bromocyclic AMP has been applied in normal ASW. Note the enhancement of $I_{\mathrm{iN}} . B$, Measurements of cAMP levels in motor neurons B 15 and in response to $\mathrm{ELH}, 5-\mathrm{HT}$, and $\mathrm{SCP}_{\mathrm{b}}$. Cells were dissected and pooled in groups of 4, and the cyclic AMP values are expressed as fmol cAMP/ nmol of total protein per cell.

activated by cAMP levels that are reached in response to $5-\mathrm{HT}$. Despite these differences, the voltage clamp and radioimmunoassay data taken together strongly implicate the role of cAMP in mediating the enhancement of $I_{\mathrm{IN}}$ by $5-\mathrm{HT}$ and $\mathrm{SCP}_{\mathrm{b}}$ in $\mathrm{B} 15$.

Similarly, in buccal ganglion motor neuron B16, bath application of 5-HT caused a significant $(p<0.005)$ increase in cAMP levels $(8.6,5-13)$ over control levels $(2.5,0.4-3.5)$ consistent with the idea that cAMP may be mediating the 5-HT-induced enhancement of $I_{\mathrm{IN}}$ in this motor neuron. However, application of ELH caused no significant increase $(p>0.1)$ in cAMP levels in B16 (2.6, 2.4-3), suggesting that the ELH-induced enhancement of $I_{\mathrm{IN}}$ in this cell is not mediated by cAMP but by some other mechanism, possibly involving cGMP.

As in $\mathrm{B} 15, \mathrm{SCP}_{\mathrm{b}}$ caused a dramatic increase in cAMP levels in $\mathrm{B} 16(132,86.6-209 ; p<0.005)$. This result was somewhat unexpected in light of the previous observation by Sossin et al. (1987) that $\mathrm{SCP}_{\mathrm{b}}$ has no observable effect on $\mathrm{B} 16$ when recording
A

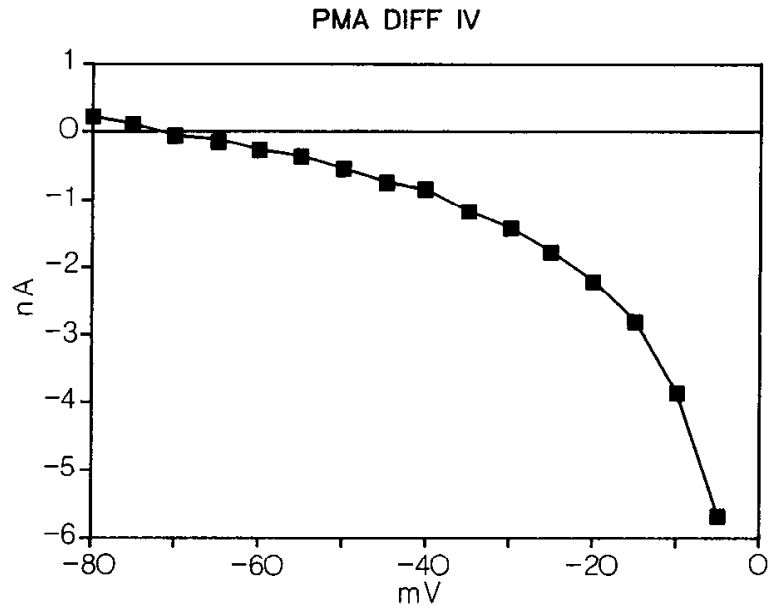

B

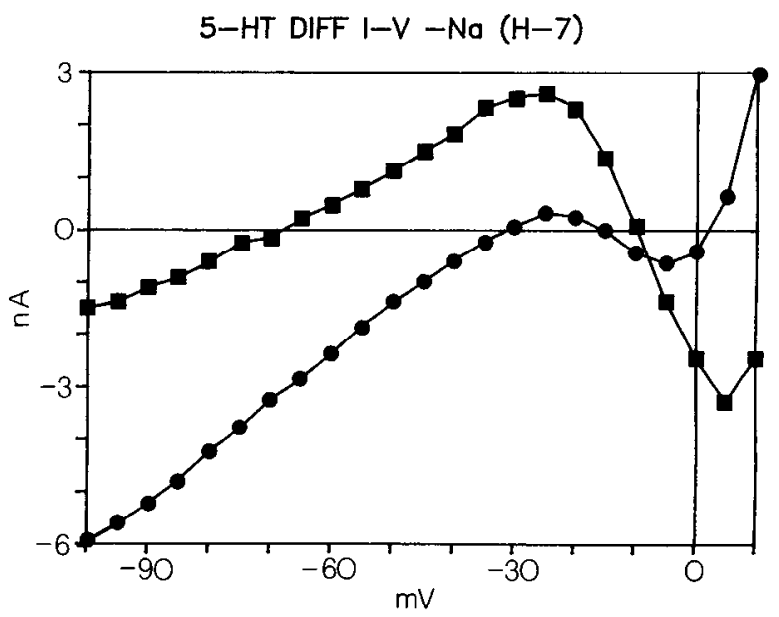

Figure 6. Involvement of $\mathrm{PKC}$ in mediating the 5-HT and $\mathrm{SCP}_{\mathrm{b}}$ responses in B15. $A$, Difference $I-V$ curves for a preparation treated with the PKC activator PMA in normal ASW. $B$, Difference $I-V$ curves for a preparation pretreated with the protein kinase inhibitor $H-7$. The experiments were conducted on the same cell in sodium-free saline containing $11 \mathrm{~mm}(\mathbb{D})$ or $55 \mathrm{~mm}(0)$ potassium. The responses shown are for 5-HT but are also representative for the $\mathrm{SCP}_{\mathrm{b}}$ responses.

from the neuron intracellularly. Resolving this discrepancy will involve a similar voltage-clamp analysis of the $\mathrm{SCP}_{\mathrm{b}}$ responses in this motor neuron.

\section{Activation of protein kinase $C$ decreases an $S$-like potassium current in $B 15$}

Protein kinase $\mathrm{C}$ (PKC), which is activated by the endogenous compound diacylglycerol, has been shown to mediate a number of neurotransmitter-induced changes in a variety of systems (Berridge, 1984). We tested the involvement of PKC in mediating the 5-HT and $\mathrm{SCP}_{\mathrm{b}}$ responses in $\mathrm{B} 15$.

In experiments performed in normal ASW, phorbol esters caused a slight enhancement of $I_{\mathrm{IN}}$ in 12 out of 30 preparations ( 9 out of 21 for PMA, 3 out of 9 for PDBI), while in 5 preparations we observed a slight decrease in this current (PMA = 4; $\mathrm{PDBU}=1$ ). More notably, a marked decrease in the S-like current was almost always observed (26 out of 30). Figure $6 \mathrm{~A}$ illustrates the difference $I-V$ curve for a preparation treated with the PKC activator PMA and is representative of experiments in which $I_{\mathrm{IN}}$ was not affected by addition of PMA. 
As in the $\mathrm{SCP}_{\mathrm{b}}$ and 5-HT responses, in sodium-free saline the reversal potential for this current was dependent on the external potassium concentration, shifting from $-68 \pm 6.2 \mathrm{mV}(n=14)$ in $11 \mathrm{~mm}$ potassium to $32 \pm 7.9 \mathrm{mV}(n=4)$ in $55 \mathrm{~mm}$ potassium. This response was specific for the phorbol esters PMA and PDBu: Similar concentrations of phorbol in the same carrier solution failed to elicit the effect $(n=5)$.

To further explore the possible role of PKC in mediating the effects of 5-HT and $\mathrm{SCP}_{\mathrm{b}}$, we applied these transmitters to preparations pretreated with the protein kinase inhibitor H-7 (Hidaka et al., 1984). Pretreatment of B15 with H-7 ( $25 \mu \mathrm{M}$ for 10 $\mathrm{min}$ ) had no observable effect on the enhancement of $I_{\mathrm{IN}}$ by 5 -HT $(n=3), \mathrm{SCP}_{\mathrm{b}}(n=3)$, or either of the FMRFamide effects $(n=4)$; however, in all cases, the 5-HT- or $\mathrm{SCP}_{\mathrm{b}}$-induced decreases of the S-like current were eliminated $(n=18$ and 16 , respectively; compare Figs. $3 A$ and $6 B$ ).

In preparations pretreated with $\mathrm{H}-7$, we were able to demonstrate the potassium dependence of the inward rectifying current by conducting the experiments in sodium-free salines, thus eliminating the components of the 5-HT and $\mathrm{SCP}_{\mathrm{b}}$ responses due to $I_{\mathrm{IN}}$ and the S-like current. Figure $6 B$ illustrates such an experiment in which 2 applications of 5-HT were added to the same cell bathed in sodium-free salines containing different potassium concentrations.

The average reversal potentials for cells in $11 \mathrm{~mm}$ potassium treated with 5-HT $(-58 \pm 6.4 \mathrm{mV}, n=4)$ or $\mathrm{SCP}_{\mathrm{b}}(-63 \pm 4.7$ $\mathrm{mV}, n=7)$ shifted more positive $(-32 \pm 0.5 \mathrm{mV}, n=3$ for $5-\mathrm{HT} ;-34 \pm 2.6 \mathrm{mV}, n=4$ for $\mathrm{SCP}_{\mathrm{b}}$ ) when the external potassium concentration was raised to $55 \mathrm{~mm}$. In addition, the magnitude of the current (measured at $-80 \mathrm{mV}$ ) increased from $-1.1 \pm 0.9 \mathrm{nA}$ (in $11 \mathrm{~mm}$ potassium) to $-5.7 \pm 2.4 \mathrm{nA}$ (in 55 mM potassium) for the 5 -HT response, and $0.8 \pm 0.3 \mathrm{nA}$ to $-5.1 \pm 2.5 \mathrm{nA}$ for $\mathrm{SCP}_{\mathrm{b}}$. Furthermore, addition of $10 \mathrm{mM}$ cesium to the external bathing solution blocked both the 5-HT and $\mathrm{SCP}_{\mathrm{b}}$ enhancement of this component $(n=7$ and 4 , respectively).

As discussed above, the 5-HT- or $\mathrm{SCP}_{\mathrm{b}}$-induced enhancement of $I_{\mathrm{INREC}}$ was not mediated by cAMP or by the activation of PKC. Therefore, we tested whether this effect might be mediated by another second messenger, $\mathrm{IP}_{3}$. B15 was voltage-clamped and impaled with a third microelectrode containing $0.5-5 \mathrm{mM}$ $\mathrm{IP}_{3}$. Pressure injection of $\mathrm{IP}_{3}$ had no effect on the $I-V$ relation of $\mathrm{B} 15(n=6)$.

\section{Role of phospholipases in the 5-HT and $S C P_{b}$ responses in $B 15$}

PKC is known to be activated by the endogenous compound diacylglycerol, which is liberated along with $\mathrm{IP}_{3}$ from phosphatidylinositol by the action of phospholipase $\mathrm{C}$ (see Berridge, 1984, for review). We have investigated the role of phospholipases in mediating the observed effects in $\mathrm{B} 15$ to $5-\mathrm{HT}, \mathrm{SCP}_{\mathrm{b}}$, and FMRFamide by examining the sensitivity of the responses to the phospholipase inhibitor $4 \mathrm{BPAB}$.

In 5 out of 6 preparations pretreated with $4 \mathrm{BPAB}(40 \mu \mathrm{M}$ for $1 \mathrm{hr}$ ), the 5-HT-induced decrease of the S-like current was blocked, while the effects of 5-HT on the inward rectifying potassium current and the voltage-dependent sodium current were unaffected by this treatment. Similarly, application of $\mathrm{SCP}_{\mathrm{b}}$ to comparably treated preparations showed normal enhancement of the inward rectifying current (experiments performed in sodium-free salines) and the inward sodium current, but the response on the S-like current was eliminated in 8 out of 9 cases.
A

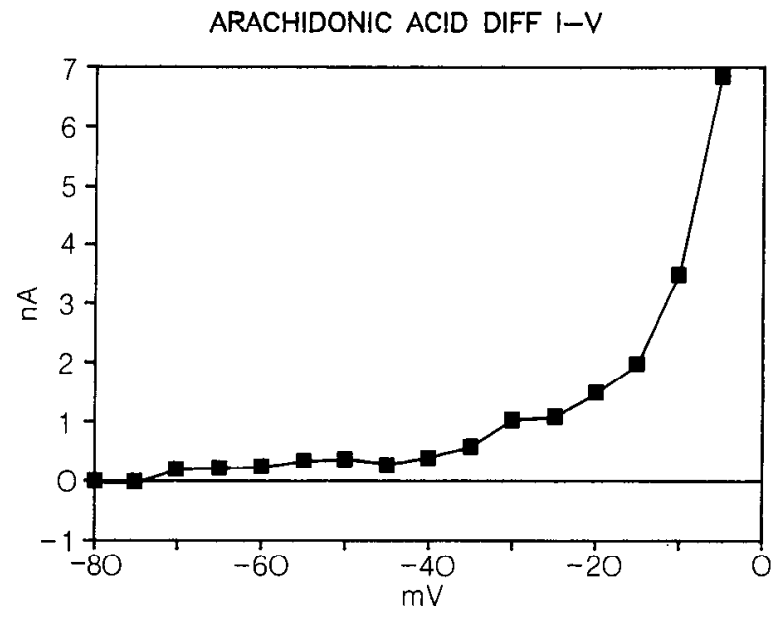

B

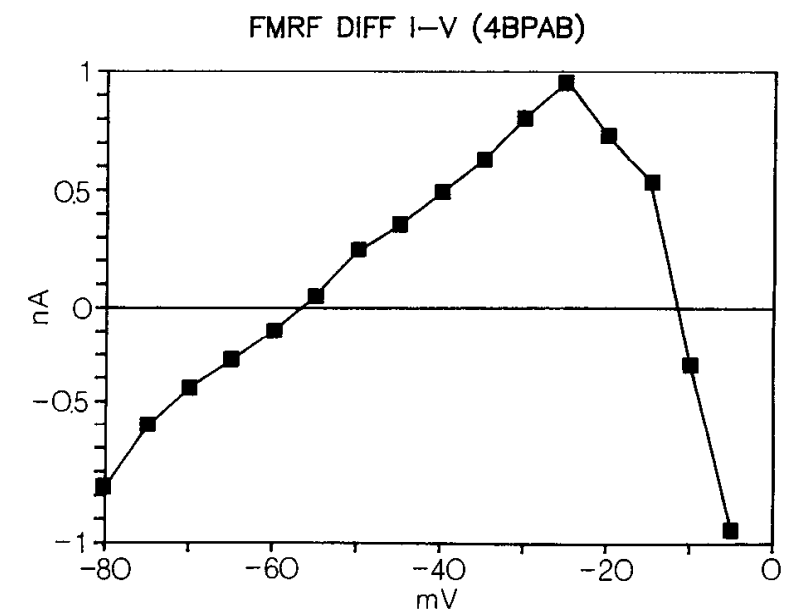

Figure 7. A cascade involving arachidonic acid may mediate part of the FMRFamide response in B15. $A$, The difference $I-V$ curve from an experiment in which arachidonic acid was pressure injected into B15. This experiment was carried out in normal ASW. $B$, The phospholipase inhibitor $4 B P A B$ blocks part of the FMRFamide response in $B 15$. The difference $I-V$ curve was constructed from a preparation pretreated with $4 \mathrm{BPAB}$ and was conducted in normal ASW.

In 5 of these cases, application of phorbol esters resulted in the normally observed decrease in $I_{\mathrm{s}}$, suggesting that block of the $\mathrm{SCP}_{\mathrm{b}}$ response on the S-like current was not due to effects of $\triangle \mathrm{BPAB}$ on the channel.

\section{Arachidonic acid mimics part of the FMRFamide response in B15}

Piomelli et al. (1987) have demonstrated that in Aplysia sensory neurons, the effects of FMRFamide are mediated by metabolites of arachidonic acid. Through the action of phospholipase $A_{2}$, which liberates arachidonic acid from phospholipids and the subsequent action of lipoxygenases to produce 12 and 5 HPETE compounds, FMRFamide causes an increase of the S-current in these neurons. We have tested the involvement of this cascade in mediating the observed FMRFamide responses in B15.

Arachidonic acid was pressure-injected into B15 while voltage-clamping the cell. Figure $7 A$ illustrates an example of one such experiment. Injection of arachidonic acid caused an increase in a current resembling $I_{S}(n=6)$; however, no effect on the voltage-dependent sodium current, $I_{\mathrm{IN}}$ was ever observed. 
A.
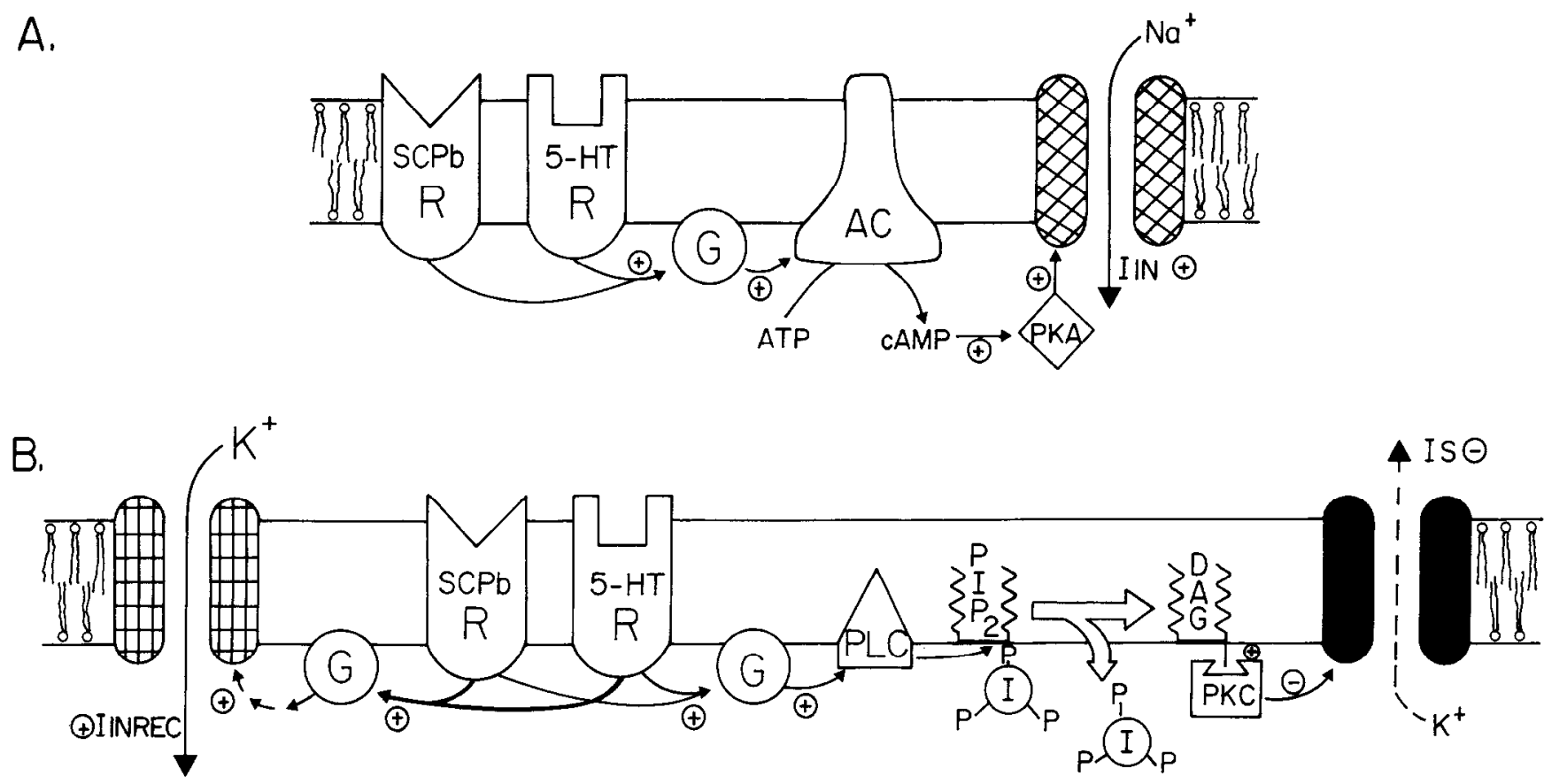

C.

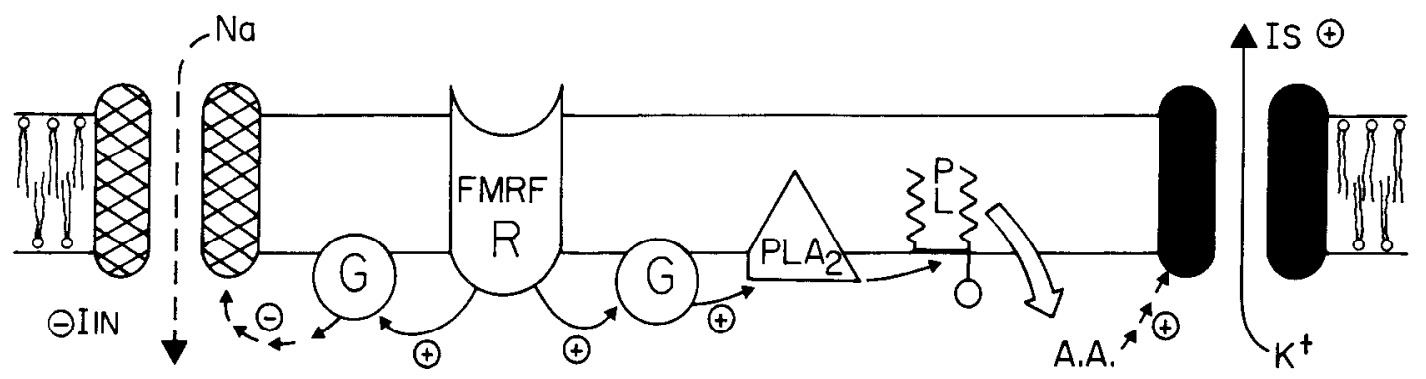

Figrire 8. Proposed models for the cellular mechanisms mediating the responses of 5-HT, SCP , and FMRFamide in B15. A, Proposed model for the activation of $I_{\mathrm{IN}}$ by $5-\mathrm{HT}$ and $\mathrm{SCP}_{\mathrm{b}}$. Binding of $\mathrm{SCP}_{\mathrm{b}}$ or $5-\mathrm{HT}$ to appropriate receptors $(R)$ activates adenyl cyclase $(A C)$, presumably through a guanine nucleotide binding protein $(G)$. The resulting rise in cAMP levels in B15 activates $I_{\text {IN }}$, which may be mediated by the cAMP-dependent protein kinase $(P K A)$. B , Proposed model for the modulation of the 2 potassium currents by $5-\mathrm{HT}$ and $\mathrm{SCP}_{\mathrm{b}}$. Binding of $\mathrm{SCP}_{\mathrm{b}}$ or $5-\mathrm{HT}$ to appropriate receptors $(R)$ activates one or more pertussis toxin-sensitive $G$ proteins $(G)$ which modulate 2 potassium currents by distinct mechanisms. The enhancement of an inward rectifying potassium current $\left(I_{\text {INREC }}\right)$ occurs via a yet unidentified pathway which does not involve cAMP, protein kinase $\mathrm{C}$, IP ${ }_{3}$, or arachidonic acid. The 5-HT- or $\mathrm{SCP}_{\mathrm{b}}$-induced decrease of an S-like current $\left(I_{\mathrm{S}}\right)$ may occur via the $\mathrm{G}$ protein activation of phospholipase C $(P L C)$ which releases diacylglycerol $(D A G)$ from phosphatidylinositol $\left(P I P_{2}\right)$. Activation of PKC by DAG subsequently results in protein phosphorylation thereby reducing $I_{\mathrm{S}}$. $C$, Proposed model for the actions of FMRFamide on $\mathrm{B} 15$. The binding of FMRFamide to receptors $(R)$ causes the activation of at least one pertussis-sensitive $\mathrm{G}$ protein. A decrease in the inward sodium current $\left(I_{\mathrm{IN}}\right)$ is mediated through a pathway yet to be identified. Enhancement of the outward S-like potassium current $\left(I_{\mathrm{S}}\right)$ occurs via the activation of phospholipase $\mathrm{A}_{2}\left(P L A_{2}\right)$ which releases arachidonic acid (A.A.) from membrane-bound phospholipids $(P L)$. Arachidonic acid or metabolites derived from it then act to increase $I_{\mathrm{s}}$.

To further explore the involvement of this cascade in mediating the FMRFamide enhancement of the S-like current, we tested whether the FMRFamide effects were sensitive to the phospholipase inhibitor, 4BPAB. In 21 out of 32 preparations pretreated with $4 \mathrm{BPAB}$ for $1 \mathrm{hr}$, we noted a $>50 \%$ reduction of this response. Of those 21 cases, the FMRFamide-induced increase of $I_{\mathrm{s}}$ was virtually eliminated in 15 . Seven of the 15 experiments were performed in normal ASW, while the others

Table 1. Summary of ionic currents modulated by 5-HT, $\mathrm{SCP}_{b}$, FMRFamide, and agents that activate second-messenger cascades, cAMP, PMA, A.A. or $\mathrm{IP}_{3}{ }^{a}$

\begin{tabular}{llllllll} 
Current & SCP $_{\mathrm{b}}$ & $5-\mathrm{HT}$ & FMRF & cAMP & PMA & A.A. & IP $_{3}$ \\
\hline$I_{\mathrm{IN}}\left(\mathrm{na}^{+}\right)$ & + & + & - & + & $\mathrm{V}$ & 0 & 0 \\
$I_{\mathrm{S}}\left(\mathrm{K}^{+}\right)$ & - & - & + & 0 & - & + & 0 \\
$I_{\mathrm{INREC}}\left(\mathrm{K}^{+}\right)$ & + & + & 0 & 0 & 0 & 0 & 0
\end{tabular}

Increases $(+)$, decreases $(-)$, or small variable responses $(\mathrm{V})$ are denoted. No measurable responses are denoted by a 0 . ${ }^{a}$ cAMP, adenosine-3':5' cyclic monophosphate; PMA, phorbol myristate acetate; A.A., arachidonic acid; $\mathrm{IP}_{3}$, inositol triphosphate. 
were conducted in no sodium. In 6 out of these preparations, only the component due to the decrease of the voltage-dependent sodium current remained. An example of one of these experiments is illustrated in Figure $7 B$.

Whether this current is the same current that is modulated by $\mathrm{SCP}_{b}, 5-\mathrm{HT}$, or cAMP is unclear. Like the cAMP response, this current reaches a peak magnitude $(1.9 \pm 1.0 \mathrm{nA}, n=6)$ in the -30 to $-15 \mathrm{mV}$ range and is not observed in cxpcriments performed in sodium-free salines. The calculated reversal potential for this response is $-8.5 \pm 2.7 \mathrm{mV}$ and, like that of the cAMP response, is below the theoretical sodium reversal potential, suggesting that this current, while principally a sodium current, may in part be a mixture of ionic conductances.

One notable difference between the modulation of $I_{\mathrm{IN}}$ by FMRFamide and cAMP is observed at voltages below $-50 \mathrm{mV}$ (compare Figs. $5 A$ and $7 B$ ). In 3 preparations, we observed an outward current at voltages between -80 and $-50 \mathrm{mV}$, as would be expected if FMRFamide modulated the same current as cAMP only in the opposite direction; however, in 3 preparations the outward current actually crossed the zero difference current axis at voltages below $-60 \mathrm{mV}$ and became inward (for example, see Fig. $7 B$ ). Resolving the issue of whether FMRFamide, $\mathrm{SCP}_{\mathrm{b}}$, and 5-HT do indeed modulate the same current will require an analysis at the level of single channels.

\section{Discussion}

Using voltage-clamp techniques, we have shown that $\mathrm{SCP}_{\mathrm{b}}$ and 5 -HT modulate 3 similar currents in B15. This observation is consistent with the notion that at many different sites, the SCPs and 5-HT have largely identical actions and may function in parallel to modulate synaptic changes (Abrams et al., 1984; Lloyd, 1986; Acosta-Urquidi, 1988). We have also demonstrated that FMRFamide modulates 2 of these same 3 currents but in the opposite direction. In Aplysia sensory neurons, FMRFamide opens the same S-channels which are closed by 5-HT and $\mathrm{SCP}_{\mathrm{b}}$ (Siegelbaum et al., 1982; Belardetti et al., 1987), albeit through mechanisms involving 2 different second-messenger systems (for review, see Belardetti and Siegelbaum, 1988). These data support the additional emerging pattern of FMRFamide and 5-HT having opposite effects at a number of different sites.

The potential roles of several second-messenger systems that may be mediating the observed transmitter-induced changes in B15 are summarized in Table 1 and Figure 8. In B15, bath application of $\mathrm{SCP}_{\mathrm{b}}, 5-\mathrm{HT}$, or membrane-permeable analogs of cAMP enhance a seemingly identical voltage-dependent inward sodium current, $I_{\mathrm{IN}}$. In addition, $\mathrm{SCP}_{\mathrm{b}}$ and 5-HT treatment increases intracellular cAMP levels in this motor neuron. Taken together, these data strongly suggest that the $\mathrm{SCP}_{\mathrm{b}}$ - and 5-HTinduced enhancement of $I_{\mathrm{IN}}$ in B15 is mediated by cAMP. In addition, in $\mathrm{B} 16$, another buccal motor neuron innervating the ARC muscle, it was shown that a similar voltage-dependent sodium current is enhanced by bath application of Aplysia egglaying hormone (ELH) (Kirk and Scheller, 1986), 5-HT, 8-bromo-cAMP, and agents that elevate intracellular cAMP levels (Kirk et al., 1988). This is likely to occur through the coupling of receptors to adenyl cyclase via a guanine nucleotide binding protein of the $G_{s}$ type (for a review of $G$ proteins, see Gilman, 1987) and the subsequent activation of channels by the cyclic AMP-dependent protein kinase (Fig. $8 A$ ), although we have not ruled out a mechanism of phosphodiesterase inactivation.
In Aplysia sensory neurons, $\mathrm{SCP}_{\mathrm{b}}$ and 5-HT cause the closure of the S-potassium channels through a cascade involving cAMP and protein kinase A (Siegelbaum et al., 1982; Abrams et al., 1984; Pollock et al., 1985; Shuster et al., 1985). While we observe a similar $\mathrm{SCP}_{\mathrm{b}}$ - and 5-HT-induced decrease of an S-like current in B15, this effect is not mediated by cAMP. In B15, $\mathrm{H}-7$, a protein kinase inhibitor shown to be specific for PKC over cAMP-dependent protein kinase in Aplysia neurons (Conn et al., 1989), blocks the 5-HT- and $\mathrm{SCP}_{\mathrm{b}}$-induced change of $I_{\mathrm{s}}$, while phorbol esters decrease $I_{\mathrm{s}}$. Taken together, these experiments suggest that activation of PKC by these transmitters results in the observed responses on the S-like current in this motor neuron (Fig. $8 B$ ). GTP binding proteins may mediate this signal-transduction process; however, further experiments are necessary to resolve this issue. Consistent with the observation that 5-HT can activate PKC in Aplysia neurons is the demonstration by Schwartz and colleagues of a 5-HT-induced translocation of PKC to membranes in sensory neurons (Sacktor et al., 1988).

The third response in $\mathrm{B} 15$ to $5-\mathrm{HT}$ and $\mathrm{SCP}_{\mathrm{b}}$ is an enhancement of an inward rectifying potassium current, $I_{\text {INREC }}$ (Katz, 1949; Hagiwara and Takahashi, 1974). Similar effects of 5-HT on inward rectifying potassium currents have been observed in other systems, including mouse hippocampal cells (Yakel et al., 1988) and Aplysia abdominal ganglion neuron R 15 (Benson and Levitan, 1983). Benson and Levitan have demonstrated that the 5-HT enhancement of $I_{\text {INREC }}$ in R 15 is mediated by cAMP (Drummond et al., 1980; Adams and Levitan, 1982). Kaczmareck and colleagues have observed a similar effect on an inward rectifying potassium current in Aplysia bag cell neurons in response to $\alpha$-bag cell peptide which is not mediated by cAMP (Kauer et al., 1987). Likewise, our data suggest that cAMP, PKC, and $\mathrm{IP}_{3}$ alone do not mediate this component of the 5-HT and $\mathrm{SCP}_{\mathrm{b}}$ responses in B15. We suggest that in B15, both 5-HT and $\mathrm{SCP}_{\mathrm{b}}$ activate a third second-messenger pathway independent of the above-mentioned cascades. One intriguing possibility is that $I_{\text {INREC }}$ is directly modulated by a guanine nucleotide binding protein ( $G$ protein) similar to the mechanism proposed for the activation of an inward rectifying potassium current by muscarinic receptors in cardiac cells (Pfaffinger et al., 1985).

How are the FMRFamide effects in B15 produced? Piomelli et al. (1987) have shown that in Aplysia sensory neurons, the FMRFamide-induced opening of S-channels are produced via a cascade involving metabolites of arachidonic acid. Our data suggest that this cascade may also be involved in the FMRFamide responses in B15. Arachidonic acid mimics part of the FMRFamide responses in B15 (the enhancement of the S-like current) and the enhancement of this current by FMRFamide was blocked by the phospholipase inhibitor 4BPAB (Fig. 8C). However, 4BPAB did not block the entire FMRFamide effect on B15; the observed decrease of $I_{\mathrm{IN}}$ by FMRFamide was not affected by this treatment, suggesting that a second pathway is involved. Alternatively, a similar, yet distinct sodium current from that affected by the other modulators may play a role in the FMRFamide response. In light of our observation that cAMP enhanced $I_{\mathrm{IN}}$ in B15, we propose that FMR Famide may in addition decrease cAMP levels in B15 by inhibiting adenyl cyclase, and we are currently testing this hypothesis. This may involve the role of an inhibitory $G$ protein of the $G_{\mathrm{I}}$ or $\mathrm{G}_{\mathrm{O}}$ type (Gilman, 1987). Alternatively, a mechanism involving $G$ protein subunit arrest of $\mathrm{G}_{\mathrm{s}}$ may account for the decrease in cyclase activity (Katada et al., 1984). Each of the transmitters examined- 
FMRFamide, $\mathrm{SCP}_{\mathrm{b}}$, and 5-HT-have multiple effects on $\mathrm{B} 15$, which raises the question of how many receptor types for each transmitter are present on this motor neuron. Cottrell and Davies (1987) have demonstrated that multiple FMRFamide receptors are present on Helix neurons. In addition, pharmacological data has revealed a number of different 5-HT receptor subtypes in mammalian systems (for review, see Peroutka, 1988). In Aplysia, segregation of 5-HT receptors on ink motor neurons was documented by Walsh and Byrne (1985). They found that bath application of 5-HT produced a mixture of current responses yet were able to isolate a particular component by restricting the application of 5-HT to a localized region of the neuron. On the other hand, Ashkenazi et al. (1987) have demonstrated that recombinant M2 muscarinic receptors expressed in a cell line lacking this receptor subtype, coupled to both adenyl cyclase and phosphoinositide turnover, suggesting that a given receptor type may be coupled to more than one second-messenger system. These 2 possibilities are not mutually exclusive in that coupling of the same receptor type to different pathways may reflect spatial constraints of receptors to effectors in different cellular locals.

These studies along with others in invertebrate and vertebrate species are beginning to define the intracellular mechanisms whereby neurons respond to a large diversity of transmitters and modulatory substances. Individual neurons maintain different receptors coupled to a variety of second-messenger systems, thereby interacting with a number of ion channels to fit the functional requirements of that cell. These functional constraints are imposed by the context of particular neuronal circuits. The selective use of these different second-messenger systems superimposed upon the networks of synaptic connections underlies, at least in part, the diversity and plasticity of the CNS.

\section{References}

Abrams, T. W., V. F. Castellucci, J. S. Camardo, E. R. Kandel, and P. E. Lloyd (1984) Two endogenous neuropeptides modulate the gill and siphon withdrawal reflex in Aplysia by presynaptic facilitation involving cAMP-dependent closure of a serotonin-sensitive potassium channel. Proc. Natl. Acad. Sci. USA. 81: 7956-7960.

Acosta-Urquidi, J. (1988) Modulation of calcium current and diverse $\mathrm{K}^{+}$currents in identified Hermissenda neurons by small cardioactive peptide b. J. Neurosci. 8: 1694-1703.

Adams, W. B., and I. B. Levitan (1982) Intracellular injection of protein kinase inhibitor blocks the serotonin-induced increase in $\mathrm{K}^{+}$ conductance in Aplysia neuron R15. Proc. Nat1. Acad. Sci. USA 79. 3877-3880.

Ashkenazi, A., J. W. Winslow, E. G. Peralta, G. L. Peterson, M. I. Schimerlik, D. J. Capon, and J. Ramachandran (1987) An M2 muscarinic receptor subtype coupled to both adenyl cyclase and phosphoinositide turnover. Science 238: 672-674.

Barish, M. E., and S. H. Thompson (1983) Calcium buflering and slow recovery kinetics of calcium-dependent outward current in molluscan neurones. J. Physiol. (Lond.) 337: 201-219.

Belardetti, F., and S. A. Siegelbaum (1988) Up-and down-modulation of single $\mathrm{K}^{+}$channel function by distinct second messengers. TINS 11: 232-238.

Belardetti, F., E. R. Kandel, and S. A. Siegelbaum (1987) Neuronal inhibition by the peptide FMRFamide involves opening of $\mathrm{S} \mathrm{K}^{+}$ channels. Nature 325:153-156.

Benson, J. A., and I. B. Levitan (1983) Serotonin increases an anomalously rectifying $\mathrm{K}^{+}$current in the Aplysia neuron R15. Proc. Natl. Acad. Sci. USA 80: 3522-3525.

Bernier, L., V. F. Castellucci, E. R. Kandel, and J. H. Schwartz (1982) Facilitory transmitter causes a selective and prolonged increase in adenosine $3^{\prime}: 5^{\prime}$-monophosphate in sensory neurons mediating the gill and siphon withdrawal reflex in Aplysia. J. Neurosci. 2: 1682-1691.
Berridge, M. J. (1984) Inositol triphosphatc and diacylglycerol as second messengers. Biochem. J. 220: 345-360.

Boyd, P. J., and R. J. Walker (1985) Actions of the molluscan neuropeptide FMRF-amide on neurones in the suboesophageal ganglia of the snail Helix aspersa. Comp. Biochem. Physiol. 81: 379-386.

Byrne, J. H. (1985) Neural and molecular mechanisms underlying information storage in Aplysia: Implications for learning and memory. Trends Neurosci. 8: 478-482.

Carew, T. J., and C. L. Sahley (1986) Invertebrate learning and memory: From behavior to molecules. Annu. Rev. Neurosci. 9: 435-487.

Cohen, J. L., K. R. Weiss, and I. Kupfermann (1978) Motor control of buccal muscles in Aplysia. J. Neurophysiol. 41: 157-180.

Colombaioni, L., D. Paupardin-Tritsch, P. P. Vidal, and H. M. Gerschenfeld (1985) The neuropeptide FMRFamide decreases both the $\mathrm{Ca}^{++}$-conductance and a cAMP-dependent $\mathrm{K}^{+}$-conductance in identified snail neurons. J. Neurosci. 5: 2533-2538.

Conn, P. J., J. A. Strong, E. M. Azhderian, A. C. Nairn, P. Greengard, and L. K. Kaczmarek (1989) Protein kinase inhibitors selectively block phorbol ester- or forskolin-induced changes in excitability of Aplysia neurons. J. Neurosci. 9: 473-479.

Connor, J. A., and P. Hockberger (1984) A novel sodium current induced by injection of cyclic nucleotides into gastropod neurones. J. Physiol. (Lond.) 354: 139-162.

Cottrell, G. A (1982) FMRFamide neuropeptides simultaneously increase and decrease $\mathrm{K}^{+}$currents in an identified neurone. Nature 296: $87-89$

Cottrell, G. A., and N. W. Davies (1987) Multiple receptor sites for a molluscan peptide (FMRFamide) and related peptides of Helix. J. Physiol. (Lond.) 382: 51-68.

Cottrell, G. A., N. W. Davies, and K. A. Green (1984) Multiple actions of a molluscan cardioexcitatory neuropeptide and related peptides on identified Helix neurones. J. Physiol. (Lond.) 356: 315-333.

DeRiemer, S. A., J. A. Strong, K. A. Albert, P. Greengard, and L. K. Kaczmarek (1983) Enhancement of calcium current in Aplysia neurons by phorbol ester and protein kinase C. Nature 313: 313-316.

Deterre, P., D. Paupardin-Tritsch, J. Bockaert, and H. M. Gerschenfeld (1982) cAMP-mediated decrease in K conductance evoked by serotonin and dopamine in the same neuron: A biochemical and physiological single-cell study. Proc. Natl. Acad. Sci. USA. 79: 7934-7938.

Drummond, A. H., J. A. Benson, and I. B. I evitan (1980) Serotonininduced hyperpolarization of an identified Aplysia neuron is mediated by cyclic AMP. Proc. Natl. Acad. Sci. USA 77: 5013-5017.

Gardner, D. (1971) Bilateral symmetry and interneuronal organization in the buccal ganglia of Aplysia. Science 173: 550-553.

Gardner, D. (1977) Interconnection of identified multiaction interneurons in buccal ganglion of Aplysia. J. Neurophysiol. 40: 349-361.

Gerschenfeld, H. M., and D. Paupardin-Tritsch (1974) On the transmitter function of 5-hydroxytryptamine at excitatory and inhibitory monosynaptic junctions. J. Physiol. (Lond.) 243: 457-481.

Gilman, A. G (1987) G proteins: Transducers of receptor-generated signals. Annu. Rev. Biochem. 56: 615-649.

Goldstein, R., H. B. Kistler Jr., H. W. M. Steinbusch, and J. H. Schwartz (1984) Distribution of serotonin-immunoreactivity in juvenile $A p l y-$ sia. Neuroscience 11: 535-547.

Green, D. S., and R. Gillette (1983) Patch- and voltage-clamp analysis of cyclic AMP-stimulated inward current underlying neurone bursting. Nature 306: 784-785.

Hagiwara, S., and K. Takahashi (1974) The anomalous rectification and cation selectivity of the membrane of a starfish egg cell. J. Membr. Biol. 18: 61-80.

Hidaka, H., M. Inagaki, S. Kawamoto, and Y. Sasaki (1984) Isoquinolinesulfonamides, novel and potent inhibitors of cyclic nucleotide dependent protein kinase and protein kinase C. Biochemistry 23 : 5036-5041.

Irvine, R. F. (1982) How is the level of free arachidonic acid controlled in mammalian cells? Biochem. J. 204: 3-16.

Jacklet, J. W., and J. Acosta-Urquidi (1985) Serotonin decreases a hackground current and increases calcium and calcium-activated currents in pedal neurons of Hermissenda. Cell. Mol. Neurobiol. 5: 407412.

Jahan-Parwar, B., A. H. Wilson Jr., and S. Fredman (1983) Role of proprioceptive reflexes in the control of feeding muscles of Aplysia. J. Neurophysiol. 49: 1469-1480.

Kandel, E. R., T. Abrams, L. Bernier, T. J. Carew, R. D. Hawkins, and J. H. Schwartz (1983) Classical conditioning and sensitization share 
aspects of the same molecular cascade in Aplysia. Cold Spring Harbor Symp. Quant. Biol. 48: 821-830.

Katada, T., J. K. Northup, G. M. Bokoch, M. Ui, and A. G. Gilman (1984) The inhibitory guanine nucleotide-binding regulatory component of adenylate cyclase. J. Biol. Chem. 259: 3578-3585.

Katz, B. (1949) Les constantes electriques de la membrane du muscle. Arch. Sci. Physiol. 3: 285-300.

Kauer, J. A., T. E. Fisher, and L. K. Kaczmarek (1987) Alpha bag cell peptide directly modulates the excitability of the neurons that release it. J. Neurosci. 7: 3623-3632.

Kirk, M. D., and R. H. Scheller (1986) Egg-laying hormone of Aplysia induces a voltage-dependent slow inward current carried by $\mathrm{Na}$ in an identified motor neuron. Proc. Natl. Acad. Sci. USA 83: 3017-3021.

Kirk, M. D., R. Taussig, and R. H. Scheller (1988) Egg-laying hormone, serotonin, and cyclic nucleotide modulation of ionic currents in the identified motor neuron B16 of Aplysia. J. Neurosci. 8: 11811193.

Klein, M., and E. R. Kandel (1980) Mechanism of calcium current modulation underlying presynaptic facilitation and behavioral sensitization in Aplysia. Proc. Natl. Acad. Sci. USA 77: 6912-6916.

Klein, M., J. Camardo, and E. R. Kandel (1982) Serotonin modulates a specific potassium current in the sensory neurons that show presynaptic facilitation in Aplysia. Proc. Nat1. Acad. Sci. USA 79: 57135717.

Kupfermann, I. (1974) Feeding behavior in Aplysia: A simple system for the study of motivation. Behav. Biol. 10:1-26.

Lloyd, P. E. (1986) The small cardioactive peptides: A class of modulatory neuropeptides in Aplysia. TINS 9: 428-432.

Lloyd, P. E., A. C. Mahon, I. Kupfermann, J. L. Cohen, R. H. Scheller, and K. R. Weiss (1985) Biochemical and immunocytological localization of molluscan small cardioactive peptides in the nervous system of Aplysia californica. J. Neurosci. 5: 1851-1861.

Lloyd, P. E., M. Frankfurt, P. Stevens, I. Kupfermann, and K. R. Weiss (1987) Biochemical and immunocytochemical localization of the neuropeptides FMRFamide, $\mathrm{SCP}_{\mathrm{A}}$, and $\mathrm{SCP}_{\mathrm{B}}$ to neurons involved in the regulation of feeding in Aplysia. J. Neurosci. 7: 1123-1132.

Mahon, A. C., P. E. Lloyd, K. R. Weiss, I. Kupfermann, and R. H. Scheller (1985) The small cardioactive peptides A and B of Aplysia are derived from a common precursor molecule. Proc. Natl. Acad. Sci. USA 82: 3925-3929.

McCamen, R. E., D. G. McKenna, and J. K. Ono (1977) A pressure system for intracellular and extracellular ejections of picoliter volumes. Brain Res. 136: 141-147.

McCarthy, M. P., J. P. Earnest, E. F. Young, S. Choe, and R. M. Stroud (1986) The molecular neurobiology of the acetylcholine receptor. Annu. Rev. Neurosci. 9: 383-413.

Newcomb, R. (1983) Peptides in the sinus gland of Cardisoma carnifex: Isolation and amino acid analysis. J. Comp. Physiol. B 153: 207-221.

Paupardin-Tritsch, D., C. Hammond, H. M. Gerschenfeld, A. C. Nairn, and P. Greengard (1986) cGMP-dependent protein kinase enhances $\mathrm{Ca}^{++}$current and potentiates the serotonin-induced $\mathrm{Ca}^{++}$current increase in snail neurones. Nature 323: 812-814.

Pellmar, T. C (1984) Enhancement of inward current by serotonin in neurons of Aplysia. J. Neurobiol. 15: 13-25.

Peroutka, S. J. (1988) 5-Hydroxytryptamine receptor subtypes. Annu. Rev. Neurosci. 11: 45-60.

Pfaffinger, P. J., J. M. Martin, D. D. Hunter, N. M. Nathanson, and B. Hille (1985) GTP-binding proteins couple cardiac muscarinic receptors to a K channel. Nature 317: 536-538.

Piomelli, D., A. Volterra, N. Dale, S. A. Siegelbaum, E. R. Kandel, J. H. Schwartz, and F. Belardetti (1987) Lipoxygenase metabolites of arachidonic acid as second messengers for presynaptic inhibition of Aplysia sensory cells. Nature 328 : $38-43$.

Pollock, J. D., L. Bernier, and J. S. Camardo (1985) Serotonin and cyclic adenosine $3^{\prime}: 5^{\prime}$-monophosphate modulate the potassium current in tail sensory neurons in the pleural ganglion of Aplysia. J. Neurosci. 5: 1862-1871.

Rosen, S. C., K. R. Weiss, J. L. Cohen, and I. Kupfermann (1982) Interganglionic cerebral-buccal mechanoafferents of Aplysia: Receptive fields and synaptic connections to different classes of neurons involved in feeding behavior. J. Neurophysiol. 48: 271-288.

Rosen, S. C., I. Kupfermann, R. S. Goldstein, and K. R. Weiss (1983) Lesion of a serotonergic modulatory neuron in Aplysia produces a specific defect in feeding behavior. Brain Res. 260: 151-155.

Ross, E. M., and A. G. Gilman (1980) Biochemical properties of hormone sensitive adenylate cyclase. Annu. Rev. Biochem. 49: 533564.

Rubin, P., J. W. Johnson, and S. Thompson (1986) Analysis of FMRFamide effects on Aplysia bursting neurons. J. Neurosci. 6: 252-259.

Sacktor, T. C., K. E. Kruger, and J. H. Schwartz (1988) Activation of protein kinase $C$ by serotonin, biochemical evidence that it participates in the mechanisms underlying facilitation in Aplysia. J. Physiol. (Paris) 83: 45-52.

Sawada, M., M. Ichinose, and T. Maeno (1987) Ionic mechanism of outward current induced by intracellular injection of inositol triphosphate into Aplysia neurons. J. Neurosci. 7: 1470-1483.

Schaefer, M., M. R. Piccciotto, T. Kreiner, R. R. Kaldany, R. Taussig, and R. H. Scheller (1985) Aplysia neurons express a gene encoding multiple FMRFamide neuropeptides. Cell 41: 457-467.

Schwartz, J. H., and L. J. Shkolnik (1981) The giant serotonergic neuron of Aplysia: A multitargeted nerve cell. J. Neurosci. 1: 606619.

Shuster, M. J., J. S. Camardo, S. A. Siegelbaum, and E. R. Kandel (1985) Cyclic AMP-dependent protein kinase closes the serotoninsensitive $\mathrm{K}^{+}$channels of Aplysia sensory neurons in cell-free membrane patches. Nature 313: 392-395.

Siegelbaum, S. A., J. S. Camardo, and E. R. Kandel (1982) Serotonin and cyclic AMP close single K channels in Aplysia sensory neurones. Nature 299: 413-417.

Sossin, W. S., M. D. Kirk, and R. H. Scheller (1987) Peptidergic modulation of neuronal circuitry controlling feeding in Aplysia. J. Neurosci. 7: 671-681.

Stryer, L. (1986) The cyclic GMP cascade of vision. Annu. Rev. Neurosci. 9: 87-119.

Thompson, S., and P. Ruben (1988) Inward rectification in response to FMRFamide in Aplysia neuron L2: Summation with transient K current. J. Neurosci. 8: 3200-3207.

Udenfriend, S., S. Stein, P. Bohlen, W. Dairman, W. Leimgruber, and M. Weigele (1972) Fluorescamine: A reagent for assay of amino acids, peptides, proteins, and primary amines in the picomole range. Science 178: 871-872.

Walsh, J. P., and J. H. Byrne (1985) Analysis of decreased conductance serotonergic response in Aplysia ink motor neurons. J. Neurophysiol. 53: 590-602.

Weiss, K. R., J. L. Cohen, and I. Kupfermann (1978) Modulatory control of buccal musculature by a serotonergic neuron (metacerebral ccll) in Aplysia. J. Neurophysiol. 41: 181-203.

Weiss, K. R., H. J. Chiel, U. Koch, and I. Kupfermann (1986) Activity of an identified histaminergic neuron in arousal of feeding behavior in semi-intact Aplysia. J. Neurosci. 6: 2403-2415.

Yakel, J. L., L. O. Trussel, and M. B. Jackson (1988) Three serotonin responses in cultured mouse hippocampal and striatal neurons. $J$. Neurosci. 8 : 1273-1284. 